\section{Ankara Üniversitesi Eğitim Bilimleri \\ Fakültesi Özel Eğitim Dergisi}

$2021,22(4), 871-893$
ARAŞTIRMA

Gönderim Tarihi: 28.05.20

Kabul Tarihi: 11.02 .21

Erken Görünüm: 10.03.21

\title{
Gelişimsel Dil Bozukluğu Olan Çocuklar: Dil Gelişimi ve Sözel Çalışma Belleği*
}

\author{
Uğur Hassamancıŏglu $\left(D_{1}\right.$
}

\author{
Özcan Doğan $\left(\mathbb{D}^{2}\right.$
}

$\ddot{O} \mathbf{z}$

Giriş: Sözel çalışma belleğinin yapısı ve işleyişi göz önünde bulundurulduğunda, gelişimsel dil bozukluğuna sahip çocukların yaşadıkları dil güçlüklerinin sözel çalışma belleği sorunlarının bir yansıması olabileceği düşünülmüştür. Bu araştırma, ilişkisel tarama modelini kullanarak gelişimsel dil bozukluğuna sahip çocukların dil gelişimleri ile sözel çalışma belleği performansları arasındaki ilişkileri ortaya koymayı amaçlamaktadır.

Yöntem: Bireysel dil ve konuşma bozuklukları terapisinden yararlanan, anadili Türkçe, 60-93 ay arasında olan ve kamu kurum ve kuruluşlarınca yapılan eğitsel değerlendirme sonucunda yalnızca dil gelişiminin desteklenmesine karar verilen 45 çocuk araştırmanın örneklemini oluşturmaktadır. Veriler Türkçe Erken Dil Gelişim Testi (TEDILL) ve Çalışma Belleği Ölçeği (ÇBÖ) kullanılarak toplanmış, sözel çalışma belleği alt boyutları ile alııı, ifade edici ve sözel dil gelişimi arasındaki ilişkiler bu çalışma kapsamında incelenmiş̧ir.

Bulgular: Sonuçlara göre sözel çalışma belleği alt boyutlarının tamamı ile çocukların dil becerileri arasında anlamlı düzeyde ilişkiler bulunmuştur. Sözel kısa süreli bellek ile alıcı dil becerileri arasındaki ilişki düzeyi ifade edici dil becerilerine nazaran daha yüksektir. Ayrıca çocukların dil gelişimleri ile sözel çalışma belleği performanslarının terapiden yararlanma sürelerine bağlı olarak değişiklik göstermediği sonucuna ulaşılmıştır.

Tartışma: Belirli bir engele bağlı olmaksızın dil gelişiminde güçlük yaşayan çocukların, sözel çalışma belleğinin alt boyutlarında farklı performanslar gösterdiği görülmüștür. Bu çocukların değerlendirme sürecine dil becerileriyle birlikte bilişsel süreçlerin de dahil edilerek bütüncül ve ayrıntılı bir değerlendirme yapılması gerektiği ileri sürülebilir.

Anahtar sözcükler: Gelişimsel dil bozuklukları, çalışma belleği, dil gelişimi, özgül dil bozukluğu, dil becerileri.

Atıf için: Hassamancıŏlu, U., \& Doğan, Ö. (2021). Gelişimsel dil bozukluğu olan çocuklar: Dil gelişimi ve sözel çalışma belleği. Ankara Üniversitesi Eğitim Bilimleri Fakültesi Özel Eğitim Dergisi, 22(4), 871-893. https://doi.org/10.21565/ozelegitimdergisi.742658

\footnotetext{
*Bu çalışma, "Özgül Dil Bozukluğu Olan Çocuklarda Sözel Çalışma Belleği, Dil ve Dikkat Becerilerinin İncelenmesi” isimli yüksek lisans tezinden üretilmiştir.

${ }^{1}$ Sorumlu Yazar: Öğr. Gör., Kapadokya Üniversitesi, E-posta: ugur.hassamancioglu@kapadokya.edu.tr, https://orcid.org/0000-0003-4108-2885
}

2Prof. Dr., Hacettepe Üniversitesi, E-posta: ozcdogan@hacettepe.edu.tr, https://orcid.org/0000-0002-3006-8159 


\section{Giriş}

Gelişimsel dil bozukluğu (GDB) kavramı, dil bozukluklarının altında yer almaktadır. Herhangi bir bozukluğa/engele bağlı olmaksızın dil gelişiminde gecikme ve/veya sorun yaşayan çocukları tanımlamak için Birincil Dil Bozukluğu, Özgül Dil Bozukluğu, İfade Edici/Karma Alıcı-İfade Edici Dil Bozukluğu gibi farklı kavramlar kullanılmaktadır. Dünya genelinde dil ve konuşma bozukluklarına sahip çocuklarla çalışan uzmanların bir araya geldikleri Delphi Consensus CATALISE Panelinde ilgili bozukluğa (Specific Language Impairment) sahip çocuklar için ortak bir terminoloji kullanılması adına 'spesifik' sözcüğünün yanıltıcı olduğu ve farklı çağrışımlara sebep olduğu düşünülerek bozukluğun 'Gelişimsel Dil Bozuklukları' ifadesi altında yer almasına karar verilmiştir (Bishop vd., 2017). Bu doğrultuda bu çalışmada da herhangi bir bozukluğa/engele bağlı olmaksızın dil gelişiminde gecikme ve/veya sorun yaşayan çocukları tanımlamak için Gelişimsel Dil Bozukluğu ifadesi kullanılmıştır. Bozukluğa sahip bireylerin dil gelişimi dışında diğer gelişim alanlarında normal gelişim gösterdikleri bilinmektedir. GDB'ye sahip bireylerin alıcı ve/veya ifade edici dil becerileri takvim yaşlarından ve zekâ bölümünden beklenen dil becerilerine nazaran oldukça sınırlıdır (Bishop, 2006). GDB olan bireylerin yaşadıkları dil sorunları zihinsel yetersizlik, işitme kaybı, motor bozukluklar, herhangi bir nörolojik bozukluk (Botting \& Conti-Ramsden, 2003) ya da otizm spektrum bozukluğu, beyin hasarı sonucu ortaya çıkan güçlükler, epileptik afazi gibi biyomedikal faktörlere bağlı olmaksızın ortaya çıkmaktadır (Özcebe vd., 2019). Bununla birlikte GDB olan çocukların muhakeme etmede, akıl yürütmede ve yürütücü işlevler gerektiren görevleri yerine getirmede zorlandıkları bilinmektedir (Kapa \& Erikson, 2019; Krzemien vd., 2019). GDB'yi açıklayabilmek adına genetik, nörobiyolojik ve bilişsel faktörler araştırılmaya devam edilmektedir. Örneğin bazı araştırmalar bozukluğun temelinde, beyinde dil ve konuşmadan sorumlu bölgelerde yer alan nöronların boyutları, sayıları, miyelizasyon derecelerinde bazı anormallikler bulunduğunu ortaya koymaktadır (Korkmaz, 2005). Diğer taraftan bilişsel süreçlerin aktif olmasıyla konuşmayı algılama, işlemleme, depolama, dili ifade etme gibi görevlerde GDB olan çocukların zorluk yaşamaları, çalışma belleği (ÇB) sorunlarının olabileceğini düşündürmektedir (Owens, 2014). GDB'yi genetik faktörlerle açıklamaya çalışan araştırmalarda ise ebeveynlerden birisinde dil bozukluğu olduğunda çocukta da GDB olabileceği (Leonard, 2000), doğruluğu tam olarak ispatlanmamış olsa da FOXP2, CNTNAP2, ATP2C2 ve CMIP genlerinin dil edinimi ve dil bozuklukları üzerinde etkili olabileceği ancak beyin fonksiyonlarının ve beyinle ilişkili bozuklukların nöropatolojisinin daha fazla aydınlatılması gerektiği sonuçlarına ulaşılmıştır (Newbury vd., 2010).

GDB'nin çocuklarda görülme sıklığına ilişkin yaş ve cinsiyete göre farklı oranlar bildirilmiştir ancak bu sıklığın yaklaşık olarak \%2.2 ile \%7 arasında olduğu görülmektedir (Beitchman \& Brownlie, 2014; Norbury vd., 2016; Tomblin vd., 1997). GDB olan çocuklar dil gelişimlerinde ve dille ilişkili becerilerde birbirlerinden farklı özellik göstermektedirler: Bazıları dili anlama ve ifade etmede zorlanırken, bazıları sadece ifade edici dil becerilerinde zorluk yaşayabilmektedirler (Turan, 2018) ve genellikle zayıf bir kelime dağarcığına sahiptirler (Prelock \& Hutchins, 2018). GDB olan çocuklar dilin biçim (Fortunato-Tavares vd., 2015; Leonard, 2001), içerik (Leonard, 2000; Owens, 2004) ve kullanım (Owens, 2004) bileşenlerinde farklı güçlükler yaşamaktadırlar.

\section{Çalışma Belleği}

ÇB, bilginin geçici olarak depolanıp aynı zamanda işlendiği bir bellek sistemi olup sınırlı kapasiteye sahiptir. ÇB'de alınan bilgilerin ilgili bileşenler tarafından analizi ve geçici olarak depolanma süreci aşamalı olarak gerçekleşmektedir (Buchsbaum, 2016). Bu araştırmada Baddeley’in çok bileşenli ÇB Modeli ele alınmıştır. Baddeley’e göre bu bileşenler görsel-mekânsal kayıt defteri (GMKD), fonolojik döngü (FD) ve merkezi yöneticidir (MY) (Baddeley, 2003). MY, ÇB'de dikkatle ilgili becerilerde (Baddeley, 2012), uzun süreli bellekle (USB) bağlantı kurulmasında (Baddeley, 2007), bilginin tutulması ve işlemlenmesi için gerekli tekrar süreçlerinin yürütülmesinde ve stratejilerin belirlenmesinde görev almaktadır. Daha sonraki çalışmalarında ise Baddeley bu bileşenlere olaysal tampon (OT) bileşenini eklemiştir. Sözel Çalışma Belleği (SÇB) "kelimeler, harfler, sayılar ya da her türlü nesne ismi gibi sözlü bilgilerin geçici olarak depolanmasından sorumludur" (Dun \& Marien, 2016) ve sözel bilgi kullanılıncaya kadar aktif bir şekilde burada tutulmaktadır (Buchsbaum, 2016). Baddeley’e göre SÇB, MY bileşenine bağlı olan FD bileşenine dayanmaktadır (Pham \& Hasson, 2014). FD, dilbilimsel süreçlerde dilin algılanması, yeni sözcüklerin kazanımı, sözel girdilerin anımsanması ve işlemlenmesiyle dilbilimsel ürünlerin öğrenilmesi sürecinde etkin görev almaktadır (Akoğlu \& Acarlar, 2014). FD bileşeni birlikte çalışan, sözel bilginin yaklaşık iki saniye tutulduğu pasif ‘fonolojik depo' ve bilgilerin taze kalmasını sağlayan, bilginin işlemlendiği aktif ‘artikülatör kontrol süreci’ yapılarından oluşmaktadır (Dun \& Marien, 2016).

Sözel bilgilerin bazı özellikleri, bilginin algılanma ve işlemlenme düzeyini etkilemektedir. Bu etkilerin ÇB performansıyla ilişkisi olduğu ifade edilmektedir (Baddeley \& Jarrold, 2007). Bunlardan ilki 'benzer ses efekti' dir. Sözel bilgiyi algılamak, kısa süreli olarak bellekte tutmak ve geri çağırmak, seslerin akustik ve fonolojik 
özelliklerine göre değişim göstermektedir. Örneğin İngilizcede, “pit, day, cow, sup, pen” sıralı ifadesi “man, cat, map, cab, can” sıralamasına kıyasla farklı özelliklere sahip olduğu için daha kolay hatırlanabilmektedir (Baddeley, 2003). 'Kelime uzunluğu etkisi' kısa kelime dizisinin uzun bir kelime dizisinden daha kolay hatırlandığı anlamına gelmektedir (Defilippi vd., 2019). Son olarak 'anlamsız ses efekti' bireyin hatırlanması gereken sözel uyaranlara dikkatini vermediği işitsel bilgi akışı eşlik ettiğinde ortaya çıkmaktadır ve bu işitsel bilgi akışı sözel uyaranın hatırlanmasında olumsuz etkiye sahiptir (Buchsbaum, 2016).

SÇB dil gelişimiyle yakından ilişkilidir. Bu ilişki alanyazında çoğunlukla dili anlama (Rusli \& Montgomery, 2017), üretme (Acheson \& Macdonald, 2009), kelime edinimi (Archibald, 2017; Currie \& Muijselaar, 2019; Stokes vd., 2017) ve okuma (Alloway vd., 2005; Lieberman, 2004) becerileri üzerinde ortaya konmuştur. Sözel bir ifade ele alındığında bu ifadenin uzunluğu, kullanılan dilin gramer yapısı, ifadenin çözümlenmesi ve anlamının çıkarılma süreci, ilgili ifadenin bellekte tutulması ve işlemlenmesini gerektirmektedir (Adams \& Gathercole, 1998). Dildeki gömülü ifadelerin anlaşılması, sözel ifadenin öğelerine ayrılması, bireyde var olan bilgi birikiminin gün yüzüne çıkarılıp yeni bilgilerle harmanlanması üzerine kuruludur (Waters \& Caplan, 2006).

ÇB’nin karmaşık ve sınırı bir kapasiteye sahip olması dolayısıyla, depolama ve işlemleme gerektiren bilgiler arttıkça bireysel farklılıklara bağlı olarak ÇB performansı düşmektedir. Bu teori GDB olan çocukların yaşadıkları sorunları açıklamak için de kullanılmıştır (Montgomery, 2003). Yaşanan ÇB güçlükleri ve GDB olan çocukların dil becerileri dillerin topolojisine göre farklılık göstermektedir, farklı dillerin yapıları GDB olan çocukların ÇB performanslarını etkilemektedir (Marton vd., 2016). ÇB'de yaşanan güçlükler üzerine çalışan bazı araştırmacılar bu güçlüklerin belirli alanlara özgü olarak ortaya çıktığını öne sürerken bazıları ise güçlüklerin MY bileşeniyle ilişkili olduğunu ve bu durumun da genel öğrenme süreci üzerinde etkili olduğunu ileri sürmektedirler (Peng \& Douglas, 2016). ÇB güçlüklerini iyileştirmek üzere çok bileşenli ÇB modelinin dikkate alınması önerilmektedir ve müdahale programları MY'den, dikkat becerilerinden, USB'den, OT'den, ÇB'nin kapasitesinden ya da dilsel bilgilerden ayrı düşünülmemelidir. Olası bir müdahalede bilişsel süreçler aşamalı ve koordineli olarak ele alınmalıdır (Schwering \& MacDonald, 2020). "ÇB'nin geliştirilmesi ve kapasitesinin arttırılması süreci fiziksel ve zihinsel egzersizlerden dikkat/meditasyona, özel derslere ve eğitimsel müdahalelere kadar uzanmaktadır" (Kronenberger \& Pisoni, 2016).

ÇB güçlükleri ve GDB olan çocuklar ile ilgili yapılan çalışmalar farklı sonuçlara ulaşmıştır. Örneğin, Marton ve diğerleri (2016), GDB olan çocukların tipik gelişen akranlarına kıyasla düşük ÇB performansına sahip olduklarını ifade ederek ÇB'nin yaşanan dil güçlükleriyle ilişkisi olduğunu dile getirmişlerdir. Kapantzoglu ve diğerleri (2015) ise çocuklarda dil bozukluğu var ya da yok ayrımının yapılmasının SÇB, aritmetik beceriler veya düşük dilbilgisellik yeterliğine sahip çocukların karıştırılmasına sebep olabileceğini bildirmiştir. GDB olan çocukların hepsinin ÇB güçlüğü yaşamadığı (Archibald \& Joanisse, 2009), dikkat sistemi, dil uyaranlarının işlemlenmesindeki farklı bozukluklar, bireylerin kullandığı stratejiler gibi diğer süreçlerin GDB olan çocukların dil gelişimleriyle ilişkili olabileceği (Archibald, 2017) sonuçlarına ulaşan çalışmalar mevcuttur. Yine Gray ve diğerleri (2019) çalışmalarında ÇB güçlüğü yaşayan her çocukta GDB olmadığı, tipik gelişen çocukların da ÇB güçlükleri yaşadığını dile getirmişlerdir. GDB olan çocuk grubu ile ilgili alanyazındaki araştırmalar ÇB'de depolama süreci (Archibald \& Griebeling, 2016; Ebbels vd., 2012), MY'nin aktif olduğu süreçler (Henry vd., 2011) ya da depolama ve işlemlemenin eşgüdümlü olduğu süreçler (Hutchinson vd., 2012) üzerinedir. Alanyazında anadili Türkçe ve GDB olan çocuklarla sözel kısa süreli bellek ve ÇB ile alıc1-ifade edici dil ve sözel dil becerileri arasındaki ilişkileri ortaya koyan araştırmalara rastlanmamıştır.

GDB olan çocukların özellikleriyle birlikte ÇB’nin işleyişi, görev aldığı süreçler ve ÇB’ye bağlı çalışan bileşenler göz önünde bulundurulduğunda, GDB'ye sahip çocukların yaşadıkları güçlüklerin, ÇB'de yaşanan sorunlar, ÇB kapasitesi ve ÇB performansının yansıması olabileceği alanyazındaki çalışmalarda ortaya konmaktadır. $\mathrm{Bu}$ doğrultuda bu çalışmada GDB olan çocukların yaşadıkları güçlüklerin SÇB alt boyutları, kapasitesi ve işleyişi ile ilişskilerinin araştırılması amaçlanmıştır. Anadili Türkçe olan, Türkçe konuşan ve GDB'ye sahip çocuklarla ilgili Türkiye'de gerçekleştirilen çalışmaların sınırlı olması, çocukların yaşadıkları güçlüklerin doğasını anlayabilme, dil güçlüklerinin SÇB ile ilişkisini kavrayabilme ve çocuklara yönelik geliştirilen müdahale programlarına katkıda bulunabilme imkânını sınırlandırmaktadır. Bu araştırma, alanyazındaki bu eksikliği gidermeyi hedeflemektedir.

GDB olan çocukların SÇB performansları ile dil gelişimleri arasındaki ilişkinin incelenmesini amaçlayan bu çalışmaya dahil edilen çocuklar özel eğitim merkezlerinden farklı sürelerde bireysel dil ve konuşma bozuklukları terapisi almaktadırlar. Çocukların aldıkları terapi süresinin SÇB performansı ve çocukların dil 
becerileri üzerinde etkileri göz önünde bulundurularak terapiden yararlanma sürelerinin SÇB performansı ve dil gelişimleri ile ilişkisi araştırılmıştır. Bu bağlamda, bu çalışmada şu sorulara yanıt aranmıştır:

1. GDB olan çocukların alıcı-ifade edici dil ve sözel dil performansları ile SÇB alt boyutları ve SÇB performansı arasında anlamlı bir ilişki var mıdır?

2. GDB olan çocukların alıcı-ifade edici dil ve sözel dil derecelendirmeleri ile SÇB düzeyleri arasındaki ilişki farklılaşmakta mıdır?

3. GDB olan çocukların SÇB performansları ile alıcı-ifade edici ve sözel dil becerileri terapiden yararlanma sürelerine bağlı olarak farklılık göstermekte midir?

\section{Yöntem}

\section{Araștırma Modeli}

Araştırmada "ilişkisel tarama modellerinden korelasyon türü" kullanılmıştır. "İlişkisel tarama modelleri, iki veya daha çok sayıdaki değişken arasında birlikte değiş̧imin varlığını ve/veya derecesini belirlemeyi amaçlayan araştırma modelleridir. Korelasyon türü ilişki araştırmalarında, değişkenlerin birlikte değiş̧im katsayıları öğrenilmeye çalışılır” (Karasar, 2019).

\section{Çalışma Grubu}

Çalışma grubunu Ankara ilinde Milli Eğitim Bakanlığına (MEB) bağlı özel eğitim kurumlarında bireysel eğitim alan GDB'li 45 çocuk oluşturmaktadır. Araştırmaya dahil edilen, GDB'ye sahip çocuklara ait demografik özellikler Tablo 1'de verilmektedir. Çocukların araştırmaya dahil edilme kriterleri, Rehberlik Araştırma Merkezlerinin (RAM) değerlendirme sonuçlarına göre yalnızca "Gelişimsel Dil Modülü” almak, anadili Türkçe olmak, başka bir engele/tanıya sahip olmamak, özel eğitim kurumlarından bireysel dil ve konuşma bozuklukları terapisi alıyor olmak ve 60-95 ay arasında kronolojik yaşa sahip olmaktır. Gelişimsel Dil Modülü, eğitsel değerlendirme ve tanı sonucunda dil ve konuşma bozukluğu olan çocukların alıcı ve ifade edici dil becerilerini desteklemek için kullanılan eğitim programını içermektedir (T.C. Milli Eğitim Bakanlığı, 2008). GDB'ye sahip çocuklar araştırmaya dahil edilmeden önce bireysel terapi aldıkları kurumların geliştirdikleri ve kullandıkları, çocuklara uyguladıkları değerlendirme araçları göz önünde bulundurularak çocukların akıcı konuşma bozukluğu, zihinsel yetersizlik, otizm gibi eşlik eden tanılara sahip olmadıkları bilgisi terapistlerin görüş bildirmeleriyle doğrulanmıştır.

\section{Tablo 1}

Gelişimsel Dil Bozukluğuna Sahip Çocuklara Ait Demografik Özellikler

\begin{tabular}{lccc}
\hline & Çocuğun demografik özellikleri & Sayı $(n)$ & Yüzde (\%) \\
\hline Cinsiyeti & Kiz & 17 & 37.8 \\
& Erkek & 28 & 62.2 \\
& $60-64$ ay & 9 & 20.0 \\
Kronolojik ayı & $65-69$ ay & 6 & 13.3 \\
& $70-74$ ay & 8 & 17.7 \\
& $75-79$ ay & 12 & 26.7 \\
& $80-84$ ay & 4 & 8.9 \\
Öğrenim düzeyi & $85-89$ ay & 3 & 6.7 \\
& $90-93$ ay & 3 & 73.3 \\
Terapiden yararlanma süresi & Anaokulu & 33 & 26.7 \\
& İlkokul 1. sinıf & 12 & 37.8 \\
\hline
\end{tabular}

\section{Veri Toplama Araçları}

Çalışmada GDB olan çocukların SÇB performanslarını belirlemek için Çalışma Belleği Ölçeği, dil gelişimlerini incelemek için Türkçe Erken Dil Gelişim Testi ve çocukların demografik özellikleriyle terapiden yararlanma süreleri hakkında bilgi almak için Kişisel Bilgi Formu kullanılmıştır. Bu araçlar aşağıda açıklanmaktadır. 


\section{Kişisel Bilgi Formu}

Bu formda, GDB'li çocuğun terapiden yararlanma süresi ile kendisine ve ailesine yönelik demografik bilgilere ulaşılmasını sağlayan sorular bulunmaktadır. Form araştırmacılar tarafından hazırlanmıştır.

\section{Çalışma Belleği Ölçeği (ÇBÖ)}

Ergül ve diğerleri (2018) tarafından 5-10 yaş arası çocukların ÇB performanslarını belirlemek üzere geliştirilmiş bir ölçektir. Ölçeğin sözel ve görsel olmak üzere iki alt alanı, her alt alan için de kısa süreli bellek (KSB) ve ÇB’yi ölçen alt boyutları bulunmaktadır. Sözel alt boyutunda rakam hatırlama (RH) (6 madde), sözcük hatırlama (SH) (4 madde), anlamsız sözcük hatırlama (ASH) (5 madde), geriye rakam hatılama (GRH) (5 madde) ve ilk sözcügü hatırlama (ISH) (4 madde) alt ölçekleri yer almaktadır. SÇB alt testlerinde her madde iki deneme içermektedir. Uygulama sırasında çocuğa bir madde en fazla bir kez yöneltilmektedir. Çocuk başarılı olduğu her bir maddeden 1 puan, başarısız olduğu maddelerden ise 0 puan almaktadır. Ölçeğin güvenilirliği test-tekrar test yöntemiyle orta ve yüksek düzeyde bulunurken, ölçüt temelli geçerliliğe sahip olduğu bildirilmiş̧ir. Ölçeğin test yarılama yöntemiyle belirlenen Cronbach Alpha katsayısı .66-.99 arasındadır. Pearson Momentler Çarpımı Korelasyon Katsayısı hesabından elde edilen değerler .41-.83 arasında değişmektedir. Yapı geçerliliğinde her bir alt ölçek içerisindeki maddelerin faktör yük değerlerinin birinci deneme uygulamasında $.40-.92$ arasında olduğu, ikinci deneme uygulamasında ise .49-.93 arasında olduğu görülmüştür”. ÇBÖ'de toplam puanlar standart puanlara dönüştürülmektedir ve bu çalışmada ölçeğin gerektirdiği gibi doğru yanıtlar ve bunlar üzerinden dönüştürülen standart puanlar kullanılmıştır. Bu çalışmada ölçeğin sözel çalışma belleği alt alanı (SÇBÖ) kullanılmıştır.

\section{Türkçe Erken Dil Gelişim Testi (TEDIL)}

Güven ve Topbaş (2015) tarafindan geliştirilen TEDILL testi 2 yaş ile 7 yaş 11 ay arasındaki çocukların dil becerilerini değerlendirmektedir. Ölçeğin aynı becerileri ölçen A ve B formları bulunmaktadır. Her iki formda da alıcı dil kısmında 25, ifade edici dil alt kısmında 39 madde yer almaktadır. Ölçeğin uygulandığı çocuk başarılı olduğu her maddeden 1 , başarısız olduğu maddelerden ise 0 puan almaktadır. Test sonunda bir ham puan elde edilir ve ham puan sözlü dil bileşik puanına dönüştürülebilir. Bu çalışmada TEDİL A formu kullanılmıştır. "TEDIL'in test-tekrar test güvenilirlik yöntemiyle korelasyon katsayısı Form A için alıcı dil .96 ifade edici dil $.89^{\prime}$ dur. Alternatif formlar güvenilirliği analizi sonuçlarına göre, alıcı dil alt testi için .68 ile .96 arasında, ifade edici dil alt testi için .60 ile .97 arasında değiştiği gözlenmiştir”. Ayrıca uygulayıcılar arasında güvenilirliği de Pearson Korelasyon Katsayısı kullanılarak belirlenmiştir. TEDİL'in geçerliliği içerik, ölçüt ve yapı olarak araştırılmışıır. Testin A formu için 2-7 yaş ortalaması alındığında alıcı dil için madde güçlük ortalaması 84, ifade edici dil için ise 74 'tür. Ayırt edicilik değeri ortalaması ise alıcı dil için 33, ifade edici dil için 55'tir. Testin dil bozukluğu olan ve normal dil gelişimine sahip çocukları ayırt edebildiği bildirilmiştir. Testin yapı geçerliliğinde ise testten elde edilen skorlar ve çocukların kronolojik yaşları arasında korelasyon incelenmiş olup katsayının .70 'ten yüksek olduğu saptanmıştır. TEDİL, dilin, anlambilgisi, biçimbilgisi ve sözdizimi bileşenlerine yönelik değerlendirme yapılmasını sağlamaktadır.

\section{Veri Toplama İşlemi ve Verilerin Analizi}

Veri toplama işlemine başlanmadan önce Hacettepe Üniversitesi-Girişimsel Olmayan Klinik Araştırmalar Etik Kurulundan gerekli izinler alınmıştır. Bunun ardından Ankara'da bulunan, dil ve konuşma terapisi eğitimi veren özel eğitim kurumlarıyla görüşülmüş, özel eğitim kurumları arasında bu araştırmanın gerçekleşmesi için aile ve çocuklardan veri toplama işlemine izin veren üç özel eğitim kurumunda Temmuz ve Ağustos 2019 tarihleri arasında araştırmanın birinci yazarı tarafından veriler toplanmıştır. RAM değerlendirmesinde sadece 'Gelişimsel Dil Modülü' kapsamında eğitim alan çocuklar kurum sorumluları tarafından belirlenmiştir. Bu çocukların eğitimcileriyle de görüşülmüsştür. Daha sonra ise çocukların ve ailelerin kurumlarda olduğu gün ve saatler belirlenmiş, ailelere ve çocuklara araştırma hakkında bilgi verilmiş ve bu çalışmaya katılımları için rızaları alınmıştır. Veri toplama işleminden önce ailelere Aydınlatılmış Onam Formu imzalatılıışır. Çocuklar bireysel eğitim almak için kurumlara geldiklerinde veriler toplanmıştır. Çocuklara önce SÇBÖ, akabinde TEDIL testleri uygulanmıştır. SÇBÖ ve TEDİL arasında ihtiyaç duyan çocuklar için 10 dakika mola verilmiştir. Motive olan ve çalışmaya devam etmeye istekli çocuklar için mola verilmemiştir. Veri toplama süresi 40 ila 60 dakika arasında değişmiştir. Aileler ise Kişisel Bilgi Formunu doldurmuştur.

Veriler SPSS Paket Programı 25.0 sürümüyle analiz edilmiştir. Veriler üzerinde betimsel analizler ve korelasyon analizleri uygulanmıştır. Veriler üzerinde önce normallik testleri uygulanmış, çarpıklık ve basıklık değeri üzerinden normal dağılım sorgulanmıştır. Normal dağılım gösterdiği kabul edilen veriler, Pearson korelasyon katsayısı, normal dağılım göstermediği kabul edilen veriler ise Spearman korelasyon katsayısıyla 
değerlendirilmiştir. Terapiden faydalanma süresinin dil gelişimi ve SÇB performansı üzerindeki farklılaşmayı ortaya koymak için Tek Yönlü Varyans Analizi (ANOVA) kullanılmıştır. Tablo 2, verilere ait tanımlayıcı bilgiler içermektedir ve verilerin normal dağılım gösterip göstermediğine karar verilmesi amacıyla oluşturulmuştur.

Tablo 2

TEDIL ve Çalışma Belleği Ölçeğine Yönelik Betimsel İstatistik Sonuçları

\begin{tabular}{lccccccc}
\hline & \multicolumn{1}{c}{ Normal dağılımın sorgulanmas1 } & & & \\
\hline & $n$ & $\bar{X}$ & Medyan & Standart hata & Standart sapma & Basıklık & Çarpıklık \\
\hline TEDİL alıcı dil alt testi & 45 & 83.42 & 83.0 & 2.211 & 14.83 & -.044 & .015 \\
TEDİL ifade edici dil alt testi & 45 & 80.93 & 83.0 & 2.063 & 13.83 & -.675 & -.249 \\
TEDİL sözel dil performansı & 45 & 78.77 & 79.0 & 2.418 & 16.22 & -.490 & -.195 \\
SÇB standart puan & 45 & 361.62 & 358.0 & 8.56 & 57.43 & .063 & .235 \\
SÇB-RH skoru & 45 & 1.466 & 1.00 & .175 & 1.179 & .301 & -.817 \\
SÇB-SH skoru & 45 & .488 & .000 & .147 & .991 & 1.936 & 2.995 \\
SÇB-ASH skoru & 45 & 1.622 & 2.00 & .132 & .886 & .636 & .943 \\
SÇB-GRH skoru & 45 & 1.711 & 2.00 & .144 & .968 & -.476 & .076 \\
SÇB-İSH skoru & 45 & .088 & .000 & .053 & .358 & 4.381 & 20.086 \\
\hline
\end{tabular}

Not: TEDIL = türkçe erken dil gelişim testi; SÇB = sözel çalışma belleği; $\mathrm{RH}$ = rakam hatıllama; $\mathrm{SH}$ = sözcük hatırlama; $\mathrm{ASH}=$ anlamsız sözcük hatırlama; GRH = geriye rakam hatırlama; İSH = ilk sözcüğü hatırlama.

Normal dağılım sorgulanırken, veri setinin çarpıklık ve basıklık değerlerinin -1.5 ila +1.5 arasında olması durumu, verilerin normal dağılım gösterdiğine karar vermek için kullanılmaktadır (Tabachnick \& Fidell, 2018). Bu bilgiden yola çıkılarak Tablo 2'ye göre SÇB 'SH' ve 'ISH' alt boyutlarının normal dağılım göstermediği görülmektedir.

\section{Bulgular}

Bu bölümde GDB olan çocukların Kişisel Bilgi Formundan elde edilen bilgilerine, TEDİL ile SÇB ölçeklerinden elde ettikleri puanların analiz sonuçlarına ve değişkenlerin ilişki düzeylerine yer verilmiştir. Şekil 1'de SÇBÖ'de sözel alt testlerde detaylı analiz yapılabilmesi adına GDB olan çocukların verdikleri doğru yanıtların frekanslarına ait yüzde değerler bulunmaktadır.

\section{Şekil 1}

Gelişimsel Dil Bozukluğu Olan Çocukların SÇBÖ Alt Alanlarına Göre Doğru Yanıt Sayılarının Yüzde Dağıllmı

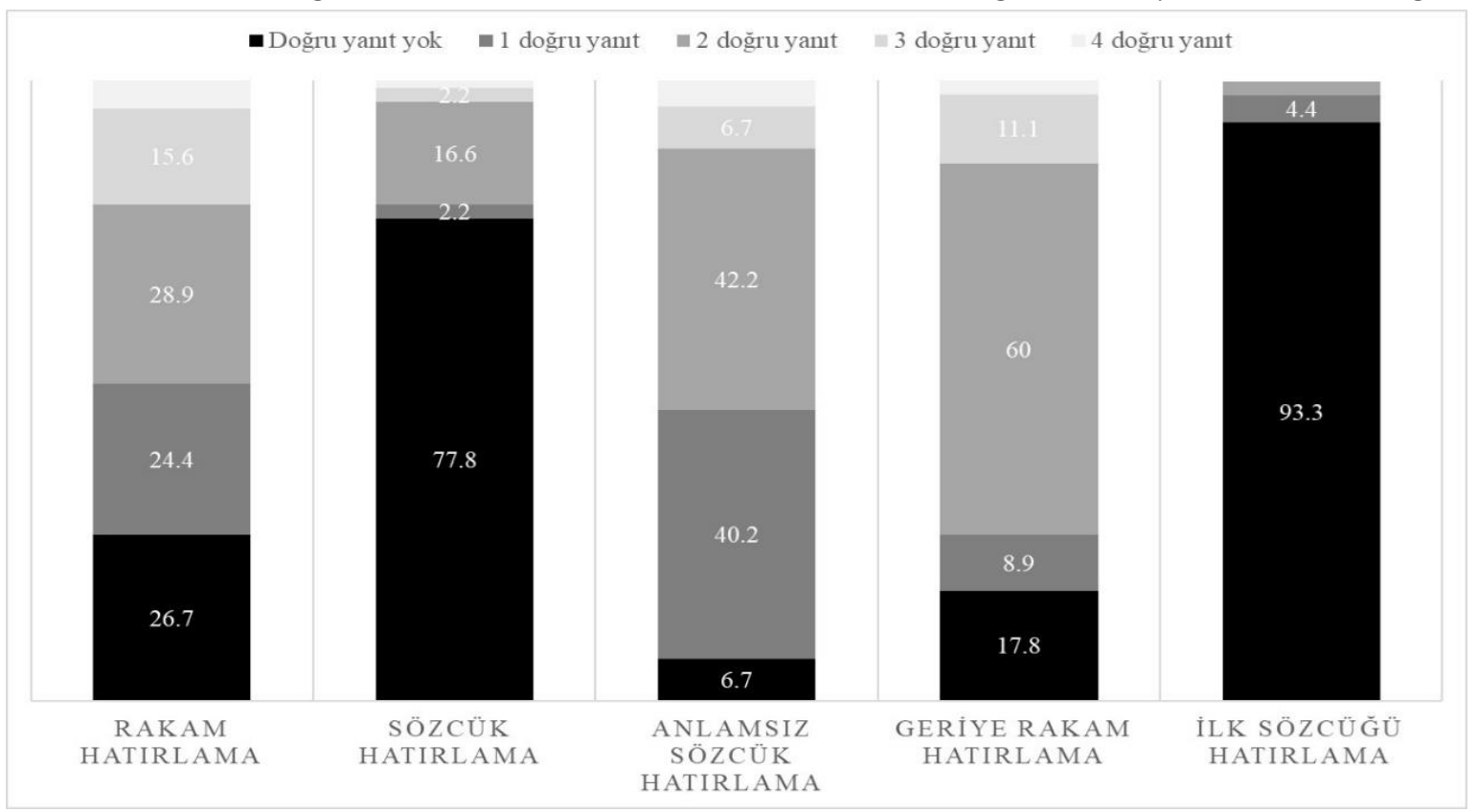

Not: SÇBÖ = sözel çalışma belleği ölçeği. 
Şekil 1'e göre GDB'li çocukların en fazla doğru yanıt verip puan aldığı alt boyut ASH iken en az puan aldıkları alt boyutun İSH olduğu görülmektedir. TEDİL derecelendirmesi ile SÇB düzeyi arasındaki olası ilişkinin varlığını incelemek amacıyla oluşturulan Tablo 3'te GDB olan çocukların TEDİL derecelendirmeleri ve SÇB düzeylerinin dağılımına yer verilmiştir.

Tablo 3

Gelişimsel Dil Bozukluğu Olan Çocukların TEDİL Derecelendirmeleri ve SÇB Düzeylerine Göre Dă̆llımı

\begin{tabular}{|c|c|c|c|c|c|c|c|c|c|c|}
\hline & & \multicolumn{8}{|c|}{ TEDİL sözlü dil bileşik puan derecelendirme } & \multirow{3}{*}{ Toplam } \\
\hline & & \multicolumn{2}{|c|}{ Çok zayıf } & \multicolumn{2}{|c|}{ Zayif } & \multicolumn{2}{|c|}{ Ortalama altı } & \multicolumn{2}{|c|}{ Ortalama } & \\
\hline & & $n$ & $\%$ & $n$ & $\%$ & $n$ & $\%$ & $n$ & $\%$ & \\
\hline \multirow{3}{*}{ SÇB düzeyi } & Çok düşük & 12 & 100 & 9 & 81.9 & 4 & 57.1 & 7 & 46.7 & 32 \\
\hline & Düşük & 0 & 0.0 & 2 & 18.1 & 3 & 42.9 & 5 & 33.3 & 10 \\
\hline & Orta & 0 & 0.0 & 0 & 0.0 & 0 & 0 & 3 & 20.0 & 3 \\
\hline Toplam & & 12 & 26.7 & 11 & 24.4 & 7 & 15.6 & 15 & 33.3 & 45 \\
\hline
\end{tabular}

Not: TEDİL = türkçe erken dil gelişim testi; SÇB = sözel çalışma belleği.

Tablo 3 incelendiğinde; TEDİL sonucuna göre çok zayıf derecelendirmeye sahip çocukların tamamının SÇB düzeyinin de çok düşük olduğu ve TEDİL derecelendirmeleri ortalamaya yaklaştıkça, SÇB düzeyinin de orta düzeye yaklaştığı görülmektedir. SÇBÖ sonuçlarına göre GDB olan çocuklardan hiçbiri Yüksek ve Çok Yüksek düzeye sahip değildir. Tablo 4'te TEDİL Alıcı, İfade Edici Dil ve Sözlü Dil Bileşik Puanı ile SÇB Standart puanı ve alt boyutları arasındaki ilişkiye ilişskin sonuçlar verilmiştir.

Tablo 4

SÇB Standart Puan ve Alt Boyutları ile TEDİL Alıcı, Ífade Edici ve Sözlü Dil Bileşik Puanları Arasındaki İlişkiler-Pearson ve Spearman Korelasyon Katsayllarl

\begin{tabular}{lcccccc}
\hline & SÇB standart puan & SÇB-RH & SÇB-SH & SÇB-ASH & SÇB-GRH & SÇB-İSH \\
\hline TEDİL alıcı dil puanı & $.528^{* *}$ & $.641 * *$ & .641 & $.389 * *$ & $.540 * *$ & .412 \\
TEDİL ifade edici dil puan1 & $.507 * *$ & $.480 * *$ & .452 & $.383 * *$ & $.477 * *$ & .161 \\
TEDİL sözlü dil bileşik puan1 & $.552 * *$ & $.604 * *$ & .612 & $.405 * *$ & $.541 * *$ & .391 \\
\hline
\end{tabular}

Not: SÇB = sözel çalışma belleği; TEDİL = türkçe erken dil gelişim testi; $\mathrm{RH}=$ rakam hatırlama; $\mathrm{SH}=$ sözcük hatırlama; ASH = anlamsız sözcük hatırlama; GRH = geriye rakam hatırlama; İSH = ilk sözcüğ̈̈ hatırlama.

$* p<.05 * * p<.01$.

Tablo 4'e göre SÇB Standart Puanı ile en yüksek ilişkinin TEDİL Sözlü Dil Bileşik Puanı arasında olduğu görülmektedir $(r=0.552, p<.01)$. Ayrıca TEDİL alıcı dil puanının SÇB alt boyutları ile ilişkisinin ifade edici alt boyutu ve sözlü dil bileşik puanlarından daha yüksek olduğu anlaşılmaktadır. SÇB alt boyutları ve TEDİL arasında ise en yüksek ilişki SH $(r=0.641, p<.01)$ ve RH $\left(r_{s}=0.641, p<.01\right)$ ile TEDİL alıcı dil puanı arasındadır. Tabloya göre değişkenler arasından sadece SÇB alt boyutlarından İSH ve TEDİL ifade edici dil puanı arasında anlamlı bir ilişki olmadığı görülmektedir $(r=0.161, p>.05)$. Tablo 5 ise GDB olan çocukların SÇB ve TEDİL standart puanlarının bireysel terapiden yararlanma sürelerine göre değişiklik gösterip göstermediği sorusunun araştırılması amaciyla oluşturulmuştur.

Tablo 5

Gelişimsel Dil Bozukluğu Olan Çocukların SÇB ve TEDİL Puanlarının Aldıkları Terapi Sürelerine Göre Tek Yönlü Varyans Analizi (ANOVA) Sonuçları

\begin{tabular}{|c|c|c|c|c|c|c|c|c|}
\hline Ölçekler & Terapi süresi & Ortalama & Standart sapma & $\operatorname{Max}$ & Min & $n$ & $F$ & $p$ \\
\hline \multirow{4}{*}{ TEDİL ifade edici dil standart puan } & $0-12$ ay & 84.7059 & 13.36 & 53.00 & 116.00 & 17 & \multirow{4}{*}{.256} & \multirow{4}{*}{.776} \\
\hline & $13-24$ ay & 80.5000 & 19.78 & 57.00 & 112.00 & 10 & & \\
\hline & $25-36$ ay & 83.8333 & 13.68 & 53.00 & 110.00 & 18 & & \\
\hline & Toplam & 83.4222 & 14.83 & 53.00 & 116.00 & 45 & & \\
\hline \multirow{4}{*}{ TEDİL alıcı dil standart puan } & $0-12$ ay & 82.2353 & 14.13 & 50.00 & 100.00 & 17 & \multirow{4}{*}{.250} & \multirow{4}{*}{.780} \\
\hline & $13-24$ ay & 78.3000 & 13.62 & 59.00 & 101.00 & 10 & & \\
\hline & 25-36 ay & 81.1667 & 14.27 & 50.00 & 100.00 & 18 & & \\
\hline & Toplam & 80.9333 & 13.83 & 50.00 & 101.00 & 45 & & \\
\hline
\end{tabular}


Tablo 5 (devami)

\begin{tabular}{ccccccccc}
\hline Ölçekler & Terapi süresi & Ortalama & Standart sapma & Max & Min & $n$ & $F$ & $p$ \\
\hline & $0-12$ ay & 80.1765 & 15.74 & 42.00 & 110.00 & 17 & & \\
TEDİL sözlü dil bileşik puan & $13-24$ ay & 75.4000 & 18.74 & 50.00 & 101.00 & 10 & .281 & .756 \\
& $25-36$ ay & 79.3333 & 15.89 & 42.00 & 102.00 & 18 & & \\
& Toplam & 78.7778 & 16.22 & 42.00 & 110.00 & 45 & & \\
& & & & & & & & \\
& $0-12$ ay & 370.7647 & 57.61 & 257.00 & 495.00 & 17 & & \\
SÇB standart puan & $13-24$ ay & 349.2000 & 61.89 & 219.00 & 464.00 & 10 & .446 & .643 \\
& $25-36$ ay & 359.8889 & 56.64 & 294.00 & 475.00 & 18 & & \\
\hline
\end{tabular}

Not: Normal dağılımın varlığı ve varyansların homojenliği varsayımları sağlandığında parametrik hipotez testleri kullanılabilir (Alpar, 2016). Bu çalışmada varyansların homojenliği ve normal dağılım varsayımları sağlandığı için ANOVA kullanılmıştır. SÇB = sözel çalışma belleği; TEDİL = türkçe erken dil gelişim testi.

GDB'li çocukların terapiden yararlanma süreleri üç grupta ele alınmıştır ve tabloya göre TEDİL puanları ve SÇB puanlarının, terapiden yararlanma sürelerine göre anlamlı bir farklılık göstermediği görülmektedir $(p>$ $.05)$.

\section{Tartışma ve Sonuç}

Araştırma soruları kapsamında, elde edilen bulgular bu bölümde 'SÇB Alt Boyutları', 'Dil Becerileri ile SÇB İlişkisi’ ve ‘Terapiden Yararlanma Süreci ile Dil Becerileri ve SÇB İlişkisi’ başlıkları altında tartışılmıştır.

\section{SÇB Alt Boyutları}

GDB’ye sahip çocukların sözel KSB ve sözel ÇB alt boyutlarında performansları incelendiğinde Şekil 1'e göre SÇB alt boyutlarında çocukların az zorlandıkları alt boyut 'ASH'dır. ASH görevinde çocuğa en az 3 kelimeli ve tek heceli anlamsız kelimelerden oluşan bir seri verilir ve çocuktan bu seriyi tekrarlaması istenir (Örneğin; meç, yöp, rit). ASH boyutu sözcüklerin fonolojik özellikleriyle ilişkilidir (Montgomery, 1995) ve anlamsız sözcüklerin sayısı arttıkça, sözcüklerin KSB'de tutulması zorlaşmaktadır. Çalışmaya katılan çocuklar, anlamsız sözcük dizisinde en fazla 4 kelimeden oluşan diziyi tekrar etmişlerdir. Bu görev FD’nin kapasitesi belirlenirken kullanılan bir ölçüttür (Archibald \& Gathercole, 2007) ve sözel bilginin kısa süreli depolanması süreçleri hakkında ipuçları vermektedir (Dun \& Marien, 2016).

Marton ve diğerleri (2016), ASH'nin doğasının henüz tam olarak anlaşılamadığını, bu görevin FD’yle birlikte dil işlemlemenin de bir ölçütü olabileceğini dile getirmişlerdir. Alanyazında da tipik gelişim gösteren çocukların (Akoğlu \& Acarlar, 2014) ve GDB olan çocukların tek heceli kelimeleri daha kolay hatırladıklarını (Dollaghan \& Cample, 1998; Kaçar, 2011), GDB olan çocukların bir ile dört heceli anlamsız kelimelerin olduğu bir dizide tek heceli kelimelerin daha fazla yer aldığ 1 en fazla 10 kelimeyi hatırlayabildiklerini (Mainela-Arnold vd., 2010b) gösteren çalışmalar mevcuttur. Archibald ve Gathercole (2006a) ASH testini en az iki heceli anlamsız kelimelerle gerçekleştirmiş ve GDB'ye sahip çocukların üç ve daha fazla heceli anlamsız sözcüklerin tekrarında zorlandıklarını ifade etmişlerdir. Aktarılan çalışmalardaki anlamsız sözcüklerin hece sayılarının kelime uzunluğu etkisiyle depolama ve işlemleme süreçlerini etkilediği bilgisi sşığında bu çalışmada kullanılan ÇBÖ'de bulunan tek heceli anlamsız kelimelerin GDB’ye sahip çocuklar tarafından işitsel olarak algılanıp, kelimelerin detaylı olarak tanıdık ses birimlerle kodlama sürecine gerek duyulmadan KSB'de kısa süre tutulduktan sonra tekrar edildikleri düşünülmektedir. Bu noktada anlamsız sözcüklerin benzer ses efekti etkisinden de bahsedilebilir. Çocuklara yöneltilen anlamsız sözcüklerin farklı akustik ve fonolojik özellikleri çocukların bilgiyi kısa bir süre tutup tekrar etmelerinde etkili olmuş olabilir.

Şekil 1'de GDB olan çocukların SÇB alt boyutlarından en fazla 'ISH' görevinde zorlandıkları görülmektedir. İSH görevinde çocuğa doğru ya da yanlış yargıda bulunacağı bir cümle verilir ve çocuktan hem cümlenin yargısını hem de cümlenin ilk sözcügünü ifade etmesi beklenmektedir (Örneğin; 'çiçek elma yer' doğru mu yanlış mı?; yanlış, çiçek). Bu görev daha çok MY bileşeninin aktif olduğu bir görevdir. Baddeley’e göre (2010) Çok Bileşenli ÇB modelinde MY bilgiler için anımsatıcı stratejiler belirler, bilginin kaybolmaması için prova süreçlerini gerçekleştirir. FD aynı zamanda MY kontrolü altında yardımcı bir sistem olarak çalışır. İSH görevinde de bireyin kısa bir süre içinde işitsel girdiyi fonolojik analiz, tekrar süreci, geri çağırma, dönüştürme ve çıktı aşamalarından geçirmesi gerekmektedir (Baddeley, 2003). Bu bilgilerin 1şığında GDB'ye sahip çocuklarda, aynı anda sözel bilgiyi kısa süreli olarak tutmanın ve işitsel olarak işlemleme yapacakları bilişsel süreçleri kullanmanın SÇB'de işlem yükünü artırdığını ve çocukların bu görevde zorlandıklarını ifade etmek mümkündür. 


\section{Dil Becerileri ile SÇB İlişkisi}

Çalışmada, alıcı ve ifade edici dil becerileriyle en yüksek pozitif ilişkiye sahip SÇB alt boyutlarının SH ve RH olduğu sonucuna ulaşılmıştır. SH, (kar, fil, buz gibi) tek heceli kelime dizilerini tekrar edilebilme görevini içermektedir. RH alt boyutunda ise çocuklardan, verilen belirli bir rakam dizisini tekrar etmeleri istenmektedir. Bu çalışmaya katılan çocuklar en fazla dört rakamın olduğu bir diziyi tekrar edebilmişlerdir (bk. Şekil 1). Bu sonuç dil becerileri ile sözel KSB'nin ilişkili olduğunu göstermektedir ve benzer şekilde alıc1-ifade edici dil becerileriyle daha çok depolama gerektiren SH (Coady vd., 2012; Mainela-Arnold vd., 2010a) ve RH (Frizelle \& Fletcher, 2015; Riches vd., 2008) gibi ÇB alt boyutlarının ilişkili olduğu sonucuna ulaşan çalışmalar mevcuttur (Gray, 2006; Vugs vd., 2016).

Dilin anlaşılması, sözel bilginin saklanması ve işlemlenmesini gerektirmektedir ve bu süreç farklı modellerle ortaya konmuştur. Modellerden birisi sınırlı ÇB kapasitesine sahip bir kimsede, saklama-işlemleme süreçlerinin birlikte yürütülmesinin zorluğu, ÇB'de saklama ya da işlemleme süreçlerinden birisinin tercih edilmesi, yani seçim yapılması üzerinedir (Akoğlu, 2011). Baddeley ve Jarrold'a (2007) göre, FD sorunları kelime öğrenimini etkilemektedir ve sözel bilginin bazı özellikleri (uzunluk, benzerlik, yakın anlam gibi) FD sorunları olan bireylerde dil edinimi sürecinde güçlüklere sebep olmaktadır. Just ve Carpenter (1992) ise dili anlamanın bireyde var olan bilgilerle yeni bilgilerin ilişkilendirildiği kodlama, geri çağırma, işlemleme hızı, dinleme düzeyi gibi karmaşık süreçleri içeren bir beceri olduğunu ifade etmektedirler. $\mathrm{Bu}$ modeller göz önünde bulundurulduğunda, bu çalışmada RH ve SH'nin ASH görevine nazaran dil becerileriyle daha yüksek düzeyde ilişkili olması, çalışma grubunun kendilerinde önceden var olan, aşina oldukları bilgilerin (örneğin ölçek maddelerindeki kar, fil, buz sözcükleri ya da rakamlar) alıcı-ifade edici dil ve sözel dil performansları üzerinde etkili olduğunu düşündürmektedir.

Alanyazında bu çalışmanın bulgularıyla örtüşmeyen, GDB olan çocukların ASH'da güçlük yaşadıklarını, ASH göreviyle bu çocukların dil becerileri arasında yüksek bir ilişki olduğunu ve ASH göreviyle GDB'nin belirlenebileceğini ifade eden çalışmalar bulunmaktadır (Dollaghan \& Campbell, 1998; Santos \& Ferre, 2018). Bunların aksine bu çalışmanın bulgularıyla örtüşen, ASH görevi ile dil becerileri arasında düşük bir ilişkinin var olduğu (Gray, 2006; Mainela-Arnold vd., 2010b) ve sözcük öğrenmeyle ASH görevinin ilişkili olmadığı (MelbyLervag vd., 2012; Schoff, 2019) sonucuna ulaşan çalışmalar da mevcuttur. Coady ve Evans (2010), ASH ile dil becerileri arasında ortaya çıkan düşük ilişkiyi açıklamak için üç olasılıktan bahsetmiştir: 1) GDB olan çocukların çalışmaya dahil edilme kriterleri (dil gelişiminde ortalamadan bir standart sapma düşük performans gösteren/standart testlerle belirlenen farklı gruplar), 2) veri toplama araçları (her çalışmanın bulgusu ilgili veri toplama aracının özelliklerine göre yorumlanmaktadır), 3) ASH testinin GDB'ye uygunluğu (dikkat eksikliği ya da yetersiz fonolojik farkındalığa sahip çocuklarda ölçüm güvenilir olmayabilir). Bu doğrultuda ASH görevi ve dil becerileri arasındaki ilişkiyi araştıran çalışmaların farklı sonuçlara ulaş̧ı̆ı görülmektedir. Örneğin veri toplama aracında anlamlı sözcüklere benzeyen ya da benzemeyen anlamsız sözcüklerin varlığı, sözcüklerin ses kayıt cihazından dinletilmesi, sözcük dizisinin benzer olup olmaması gibi faktörlerin sonuçları etkileyebileceği düşünülmektedir. Ayrıca bu çalışmada örneklem grubunu Türkiye'de sadece ilgili kurum ve kişilerce yapılmış eğitsel ve tıbbi değerlendirmeler sonucu dil güçlüğü yaşadığına karar verilen çocuklar oluşturmaktadır. Diğer ülkelerde GDB olan çocuk grubunun belirlenmesi ve tanılanması süreçlerinin Türkiye'dekinden farklı olmasının, diğer ülkelerdeki çocuklar üzerinde yapılan çalışmalarda farklı sonuçların elde edilmesinde etkili olabileceği düşünülmektedir. Dolayısıyla yukarıda belirtildiği üzere örneklem belirleme kriterleri, GDB olan çocukların özellikleri ve kullanılan ölçme aracı dil becerileriyle ASH görevi arasındaki nispeten düşük ilişkiyi açıklayabilir.

$\mathrm{Bu}$ araştırmanın sonuçlarına göre GRH görevi alıcı-ifade edici dille ilişkiliyken İSH görevi sadece alıcı dil becerileriyle ilişkilidir. Alanyazında İSH'yle paralel olarak ÇB performansını değerlendiren farklı tekniklerin kullanıldığı görülmektedir. Örneğin Mainela-Arnold ve Evans (2005) çalışmalarında çocuklara cevabı evet-hayır olan ve cümlede hangi kelimeyi hatırladıklarını belirleyen sorular sormuşlardır ve bu çalışmanın bulgularını destekler nitelikte bu görevin alıcı dille ilişkisi olduğu ancak ifade edici dille anlamlı bir ilişkisi olmadığı sonucuna ulaşmışlardır. Yine bu çalıșmanın bulgularını destekleyen başka bir araştırmada İSH göreviyle dili anlama becerisi ve kelime dağarcığının ilişkili olduğu sonucuna ulaşılmıştır (Ziethe vd., 2013). Archibald ve Gathercole, (2006b) ÇB'nin aktif olduğu bilgi işlem sürecinde GDB'ye sahip çocukların zorlanmalarını, çocukların bilgilerin depolanmasında yaşadıkları soruna bağlarken, bazı çalışmalar (Vugs vd., 2014) çocukların bilgiyi depolama ve alma işlemlerinde sadece sözel değil görsel ÇB'nin de aktif olduğunu ve çocukların bu kadar bilişsel yükün altından eş zamanlı olarak kalkmakta zorlandıklarını, buna bağlı olarak da dilbilimsel bilgilerin işlemleme kapasitesinin yetersiz kaldığı sonuçlarına ulaşmışlardır. 
$\mathrm{Bu}$ çalışmada SÇB'de bilginin işlemlendiği süreçlerle dil gelişimi arasındaki ilişkiyi ortaya koyan sonuçların alanyazında yapılan diğer çalışma sonuçlarıyla tutarlı olduğu görülmektedir. Bilginin depolanmasını içeren süreçlerin, bilginin işlemlenmesini içeren süreçlere nazaran dil becerileriyle daha yakından ilişkili olduğu görülmektedir (bk. Tablo 4). Alıcı-ifade edici dilin gelişimi ve SÇB'nin bir parçası olan FD’nin de görev ve işlevleri düşünüldüğünde, SÇB ile alıcı dil ilişkisi düzeyinin ifade edici dil ilişkisine nazaran daha yüksek olması şaşırtıcı değildir. SÇB ve dil becerileri arasındaki ilişkiyle ilgili bu çalışmanın bulgularını destekler şekilde alanyazında düşük ÇB kapasitesine ve performansına bağlı olarak GDB olan çocukların karmaşık ve uzun cümleleri anlama (Montgomery, 2000) ile anlatım becerilerinde güçlük yaşadıklarını (Archibald \& Griebeling, 2016) ve zayıf dilbilgisi ve sözcük dağarcı̆̆ına sahip olduklarını (Kim, 2016) gösteren çalışmalar bulunmaktadır. GDB'ye sahip çocukların yer aldığı grup heterojen bir gruptur. Çocukların dilin bileşenlerinde yaşadıkları zorluklar da farklılaşmaktadır (Turan, 2018). Bu noktada bu çalışmanın sonuçları SÇB kapasitesi ve performansının dil gelişimiyle ilişkili olduğu yönündeki bulgularını desteklerken ortaya çıkan orta düzey ilişki, GDB olan çocukların dil gelişimleriyle bağlantılı olabilecek diğer çevresel, biyolojik ya da farklı bilişsel süreçlerin de var olabileceği şeklinde yorumlanmaktadır. Örneğin kırsalda yaşayan ve GDB olan çocukların dil becerilerinin şehirde yaşayan GDB olan çocuklara nazaran önemli ölçüde düşük olduğunu (Kornilov vd., 2016), GDB olan çocukların işitsel işlemleme eksikliklerine bağlı olarak ses-anlam haritası oluşturmada zorlandıklarını (Quam vd., 2020), farklı genlerin (Newbury vd., 2010) ve DNA dizilimlerinin (Chen vd., 2017) yaşanılan dil güçlükleri üzerinde etkili olabileceğini gösteren çalışmalar bulunmaktadır. GDB olan çocukların yaşadıkları güçlüklerin tek bir etmene bağlı olması düşüncesinden çok, bu durumun birden fazla faktörle açıklanabilmesi muhtemel görünmektedir.

Çalışmaya katılan çocuklardan hiçbiri yüksek veya çok yüksek düzeyde SÇB performansı göstermemektedir. Bu bulgu şaşırtıcı değildir. Alanyazında GDB olan çocukların ÇB güçlükleri yaşadıklarını gösteren çalışmalar mevcuttur (Archibald \& Griebeling, 2016; Ebbels vd., 2012; Ergül vd., 2018; Hutchinson vd., 2012). Bu çalışma sonucunda dikkati çeken nokta SÇB düzeyi çok düşük olup TEDİL derecelendirmesi ortalama/ortalama altı olan çocuklara rastlanmasıdır (bk. Tablo 3). Bu durum, bireysel farklılıklar ve çocukların faydalandıkları dil ve konuşma terapisi sonucu ortaya çıkmış olabilir. ÇB kapasitesi bireyden bireye farklılık göstermektedir ve ÇB'nin eksiksiz çalışması için bireyin gereksinimlerin belirlenmesi ve karşılanması gerekmektedir. Birey kendinde var olan bilgilerle ve geliştirdiği stratejik yaklaşımlarla ÇB görevlerini yerine getirmektedir (Daily vd., 2001). Bireyin dikkat yoğunluğu da kodlamayı, USB'de bilginin tutulmasını ve ÇB kapasitesi kullanımını etkileyebilmektedir (Miller vd., 2019). Dolayısıyla çocukların faydalandıkları terapinin hedefleri, terapide kullanılan yöntemler, çocukta var olan bilgi birikimi, bilginin işlemleme stratejisi, dikkat becerileri gibi bireye bağlı faktörlerin bu sonucu ortaya çıkarması muhtemeldir.

\section{Terapiden Yararlanma Süreci ile Dil Becerileri ve SÇB İlişkisi}

Bu çalışmada örneklem grubunu oluşturan çocuklar farklı sürelerde bireysel dil ve konuşma terapisinden faydalanmaktadırlar. Çocukların dil becerileri ile SÇB performanslarının bireysel terapiden yararlanma sürelerine göre anlamlı bir değişiklik göstermediği sonucuna ulaşılmıştır (bk. Tablo 6). Montgomery ve diğerleri (2010), GDB olan çocukların bellek kullanımı gibi alternatif yaklaşımlarla bilişsel becerilerinin desteklenmesi gerektiğini önermektedirler. Bilişsel becerilere bağlı olarak çocuklara FD stratejilerinin öğretilmesi, dil sorunlarının önüne geçilmesi için destekleyici nitelikte olabilmektedir. Bu stratejiler, bilginin korunmasıyla birlikte işlemlenmesini de içermektedir. Dil gelişimi ve bellek kapasitesi kullanımını desteklemek üzere tekerlemeler, tanıdık olmayan veya çocuklara komik gelen anlamsız kelimelerin tekrar edilmesi, kafiyeli kelime bulma oyunları, yeni kelime öğreniminde bilinen bir kelimeden yola çıkılması ve ileriki zamanlarda da uzun bir cümlenin bellekte kalması için işlemlenmesi üzerine stratejiler oluşturma çabaları kullanılabilmektedir (Montgomery, 2002).

SÇB’yi güçlendiren işitsel uyaranları sıraya koyma ve belekte tutma, sözcük, rakam, ilk sözcüğü hatırlama gibi görevleri içeren eğitim amaçlı kullanılan oyunlar bulunmaktadır (Vugs vd., 2017). ÇB odağında dil gelişimini destekleyen, strateji geliştirme (Dodwell \& Bavin, 2010), kapasite kullanımı ve birden fazla görevi manipüle edebilmeyi amaçlayan yöntemlerin destekleyici olduğunu gösteren çalışmalar da bulunmaktadır (Banales vd., 2015; Blacker \& Curby, 2014; Brewin \& Smart, 2005; Vugs vd., 2014). Bu çalışmada çocukların terapi sürelerinin değişmesiyle dil ve SÇB performanslarının farklılaşmamış olması, süre yerine terapinin içeriğinin, becerilerin öğretiminde kullanılan yöntem ve tekniklerin, materyallerin ve sadece dil gelişimine değil bilişsel becerilere de odaklanarak bütüncül şekilde hazırlanmış programların daha destekleyici olabileceğini düşündürmektedir.

Sonuç olarak GDB olan çocukların dil gelişimleriyle SÇB arasında bir ilişkinin var olduğu görülmektedir. Dil becerileri çok zayıf derecelendirmede olan çocukların SÇB performanslarının da çok düşük düzeyde olduğu 
sonucu bu ilişkiyi desteklemektedir. Çalışmada, alıcı dil gelişiminin SÇB ile daha yakından ilişkisi olduğu, çocukların daha çok SÇB'de sözel bilgiyi bellekte tutmayı tercih ettikleri ve işlemleme yapmaları gereken, aktif süreçlerde zorlandıkları sonuçlarına ulaşılmışıı. Ayrıca çocukların alıcı-ifade edici dil ve sözel dil performansları üzerinde, çocuklarda önceden var olan ve aşina oldukları bilgilerin etkili olduğu görülmüştür.

Dilin topolojisine bağlı olarak anadili Türkçe ve GDB olan çocukların yaşadıkları güçlükler ile SÇB ilişkisinin yanı sıra, bu güçlükler üzerinde etkili olabilecek dikkat becerileri, işlemleme hızı, yeni bilgiyi edinme ve kullanma için stratejiler geliştirme gibi konular yapılacak sonraki çalışmalarda araştırabilir. Çocukların görsel ÇB performansları değerlendirilip bunların dil gelişimiyle ilişkisinin incelenmesi, SÇB'nin sözcük dağarcığı, okuma-yazma, fonolojik farkındalık gibi beceriler üzerine etkisinin araştırılması ve ÇB odağında dil gelişim destekleyici müdahale programları geliştirilerek etkilerinin sorgulanması alana daha fazla katkı sağlayabilir.

Belirli bir engele bağlı olmaksızın dil gelişiminde yaşadıkları sorunlar göz önünde bulundurulduğunda GDB olan çocukların tıbbi ve eğitsel değerlendirme süreçlerinde dil gelişimlerinin yanı sıra bilişsel becerilerinin de ayrıntılı olarak değerlendirilmesi ve bireysel farklıkların odağında gereksinimlerinin belirlenmesinin bireye özgü destek programlarının yapılandırılmasında etkili olacağı düşünülmektedir. Çocuklarda SÇB değerlendirilirken SÇB'nin alt boyutlarını ayrı ayrı ele almak ve yorumlayabilmek mümkün olsa da Çok Bileşenli CB Modeli farklı görevleri olan bileșenlerin bir arada koordineli çalıștığı bir sistemdir. Sistemde güçlü ve zayıf işleyişin belirlenmesiyle bütüncül şekilde hazırlanan destek programları uygun sağaltımların gerçekleştirilmesinde önemlidir.

\section{Sinırlılıklar}

Bu çalışma doğrudan tanılanması güç, özel ve zor ulaşılan GDB’ye sahip 45 çocuk ve bu çocukların ebeveynleriyle, kurum ve kişilerin çocuklar üzerinde yaptıkları değerlendirme sonuçlarıyla, bünyesinde araştırma gerçekleştirilmesine izin veren üç özel eğitim kurumuyla ve çalışma belleğinin sözel alanıyla sınırlıdır.

\section{Yazarların Katkı Düzeyleri}

Araştırmanın birinci yazarı verilerin toplanmasında görev almıştır. Araştırmada kullanılan verilerin analizi, makalenin yazım süreci ve düzenlemeler iki yazarın da desteği ile gerçekleşmiştir. 


\section{Kaynaklar}

Acheson, D. J., \& Macdonald, M. C. (2009). Twisting tongues and memories: Explorations of the relationship between language production and verbal working memory. Journal of Memory and Language, 60(3), 329-350. https://doi.org/10.1016/j.jml.2008.12.002

Adams, A. M., \& Gathercole, S. E. (1998). Limitations in working memory: Implications for language development. International Journal of Language \& Communication Disorders, 35(1), 95-116. https://doi.org/10.1080/136828200247278

Akoğlu, G. (2011). Gelişimsel dil bozukluğu olan ve normal gelişim gösteren çocuklarda sözdizimi anlama becerileri ile sözel çalışma belleği iliş̧kisinin incelenmesi [Investigation of relationship between verbal working memory and syntax comprehension skills on children with developmental language disorders and typically developing children] (Tez Numarası: 300708) [Doktora tezi, Ankara Üniversitesi]. Yükseköğretim Kurulu Ulusal Tez Merkezi.

Akoğlu, G., \& Acarlar, F. (2014). Gelişimsel dil bozukluklarında söz dizimi anlama ve sözel çalışma belleği ilişkisinin incelenmesi [Relationship between syntax comprehension and verbal working memory of children with developmental language disorders]. Türk Psikoloji Dergisi, 29(73), 89-103.

Alloway, T. P., Gathercole, S. E., Adams, A. M., Willis, C., Eaglen, R., \& Lamont, E. (2005). Working memory and phonological awareness as predictors of progress towards early learning goals at school entry. The British Psychological Society, 23(3), 417-426. https://doi.org/10.1348/026151005X26804

Alpar, R. (2016). Spor, sağlık ve eğitim bilimlerinden örneklerle-Uygulamalı istatistik ve geçerlilik-güvenilirlik [With examples from sports, health and education sciences-Applied statistics and validity-reliability]. Detay Yayıncilık.

Archibald, L. M. (2017). Working memory and language: A review. Child Language Teaching and Therapy, 33(1), 5-17. https://doi.org/10.1177/0265659016654206

Archibald, L. M., \& Gathercole, S. E. (2006a). Nonword repetition: A comparison of test. Journal of Speech, Language, and Hearing Research, 49(5), 970-982. https://doi.org/10.1044/1092-4388(2006/070)

Archibald, L. M., \& Gathercole, S. E. (2006b). Visuospatial immediate memory in specific language impairment. Journal of Speech, Language, and Hearing Research, 49(2), 265-277. https://doi.org/10.1044/1092$\underline{4388(2006 / 022)}$

Archibald, L. M., \& Gathercole, S. E. (2007). Nonword repetition and serial recall: Equivalent measures of verbal $\begin{array}{llll}\text { short-term memory? } \quad \text { Applied } & \text { Psycholinguistics, }\end{array}$ https://doi.org/10.1017/S0142716407070324

Archibald, L. M., \& Griebeling, K. H. (2016). Rethinking the connection between working memory and language. International Journal of Language \& Communication Disorders, 51(3), 252-264. https://doi.org/10.1111/1460-6984.12202

Archibald, L. M., \& Joanisse, M. F. (2009). On the sensitivity and specificity of nonword repetition and sentence recall to language and memory impairments in children. Journal of Speech, Language, and Hearing Research, 52(4), 899-914. https://doi.org/10.1044/1092-4388(2009/08-0099)

Baddeley, A. (2003). Working memorỷ looking back and looking forward. Nature Reviews/Neuroscience, 4(10), 829-875. https://doi.org/10.1038/nrn1201

Baddeley, A. (2007). Working memory, thought and action. Oxford Psychology Series.

Baddeley, A. (2010). Working memory. Current Biology, 20(4), 136-140. https://doi.org/10.1016/j.cub.2009.12.014

Baddeley, A. (2012). Working memory: Theories, models, and controversies. Annual Review of Psychology, 63, 1-29. https://doi.org/10.1146/annurev-psych-120710-100422

Baddeley, A., \& Jarrold, C. (2007). Working memory and down syndrome. Journal of Intellectual Disability Research, 51(12), 925-931. https://doi.org/10.1111/j.1365-2788.2007.00979.x 
Banales, E., Kohnen, S., \& McArthur, G. (2015). Can verbal working memory training improvereading? Cognitive Neuropsychology, 32(3), 1-29. https://doi.org/10.1080/02643294.2015.1014331

Beitchman, J. H., \& Brownlie, E. (2014). Language disorders in children and adolescent. Hogrefe Publishing.

Bishop, D. V. (2006). What causes specific language impairment in children? Current Directions in Psychological Science, 15(5), 217-221. https://doi.org/10.1111/j.1467-8721.2006.00439.x

Bishop, D. V., Snowling, M., Thompson, P. A., Greenhalgh, T., \& CATALISE-2 Consortium. (2017). Phase 2 of CATALISE: A multinational and multidisciplinary Delphi consensus study of problems with language development: Terminology. The Journal of Child Psychology and Psychiatry, 58(10), 1068-1080. https://doi.org/10.1111/jcpp.12721

Blacker, K. J., \& Curby, K. M. (2014). Effects of action video game training on visual working memory. Journal of Experimental Psychology: Human Perception and Performance, 40(5), 1992-2004. https://doi.org/10.1037/a0037556

Botting, N., \& Conti-Ramsden, G. (2003). Characteristics of children with specific language impairment. In L. Verhoeven, \& H. van Balkom (Eds.), Classificaton of developmental language disorder theoretical issues and clinical implications (pp. 23-38). Lawrence Erlbaum Associates.

Brewin, C. R., \& Smart, L. (2005). Working memory capacity and suppression of intrusive thoughts. Journal of Behavior Therapy and Experimental Psychiatry, 36(1), 61-68. https://doi.org/10.1016/j.jbtep.2004.11.006

Buchsbaum, B. R. (2016). Working memory and language. G. Hickok, \& S. L. Small (Eds.), Neurobiology of language (pp. 863-875). Academic Press.

Chen, X. S., Reader, R. H., Hoischen, A., Veltman, J. A., Simpson, N. H., Francks, C., Newbury, D. F., \& Fisher, S. E. (2017). Next-generation DNA sequencing identifies novel gene variants and pathways involved in specific language impairment. Scientific Reports, 46105(7). https://doi.org/10.1038/srep46105

Coady, J. A., \& Evans, J. L. (2010). Uses and interpretations of non-word repetition tasks in children with and without specific language impairments (SLI). International Journal of Language \& Communication Disorders, 40(1), 1-40. https://doi.org/10.1080/13682820601116485

Coady, J. A., Mainela-Arnold, E., \& Evans, J. L. (2012). Phonological and lexical effects in verbal recall by children with specific language impairments. International Journal of Language \& Communication Disorders, 48(2), 144-159. https://doi.org/10.1111/1460-6984.12005

Currie, N., \& Muijselaar, M. M. (2019). Inference making in young children: The concurrent and longitudinal contributions of verbal working memory and vocabulary. Journal of Educational Psychology, 111(8), 1416-1431. https://doi.org/10.1037/edu0000342

Daily, L. Z., Lovett, M. C., \& Reder, L. M. (2001). Modeling individual differences in working memory performance: A source activation account. Cognitive Science, 25(3), 315-353. https://doi.org/10.1207/s15516709 $\operatorname{cog} 2503 \_1$

Defilippi, A. C., Garcia, R. B., \& Galera, C. (2019). Irrelevant sound interference on phonological and tonal working memory in musicians and nonmusicians. Psicologia: Reflexão e Crítica, 32(2), 1-10. https://doi.org/10.1186/s41155-018-0114-Z

Dodwell, K., \& Bavin, E. L. (2010). Children with specific language impairment: An investigation of their narratives and memory. International Journal of Language \& Communication Disorders, 43(2), 201-218. https://doi.org/10.1080/13682820701366147

Dollaghan, C., \& Campbell, T. F. (1998). Nonword repetition and child language impairment. Journal of Speech Language and Hearing Research, 41(5), 1136-1146. https://doi.org/10.1044/jslhr.4105.1136

Dun, V. K., \& Marien, P. (2016). Cerebellar-induced aphasia and related language disorders. In P. Marien, \& M. Manto (Eds.), The linguistic cerebellum (pp. 107-133). Academic Press.

Ebbels, S. H., Dockrell, J. E., \& van der Lely, H. K. (2012). Non-word repetition in adolescents with specific language impairment (SLI). International Journal of Language \& Communication Disorders, 47(3), 257 273. https://doi.org/10.1111/j.1460-6984.2011.00099.x 
Ergül, C., Yılmaz, Ç. Ö., \& Demir, E. (2018). 5-10 yaş grubu çocuklara yönelik geliştirilmiş çalışma belleği ölçeğinin geçerlik ve güvenirliği [Validity and reliability of the working memory scale for children aged 5-10 years]. Eğitimde Kuram ve Uygulama, 14(2), 187-214. https://doi.org/10.17244/eku.427280

Frizelle, P., \& Fletcher, P. (2015). The role of memory in processing relative clauses in children with specific language impairment. American Journal of Speech-Language Pathology, 24(1), 47-59. https://doi.org/10.1044/2014_AJSLP-13-0153

Fortunato-Tavares, T., Andrade, C. R., Befi-Lopes, D., Limongi, S. O., Fernandes, F. D., \& Schwartz, R. G. (2015). Syntactic comprehension and working memory in children with spesific language impairment, autism or down syndrome. Clinical Linguistics \& Phonetics, 29(7), 499-522. https://doi.org/10.3109/02699206.2015.1027831

Gray, S. (2006). The relationship between phonological memory, receptive vocabulary, and fast mapping in young children with specific language impairment. Journal of Speech, Language, and Hearing Research, 49(5), 955-969. https://doi.org/10.1044/1092-4388(2006/069)

Gray, S., Fox, A., Green, S., Alt, M., Hogan, T. P., Petscher, Y., \& Cowan, N. (2019). Working memory profiles of children with dyslexia, developmental language disorder, or both. Journal of Speech, Language, and Hearing Research, 62(6), 1839-1858. https://doi.org/10.1044/2019 JSLHR-L-18-0148

Güven, S., \& Topbaş, S. (2015). Erken dil gelişimi testi üçüncü versiyonu'nun üçüncü versiyonu'nun (TELD-3) Türkçe'ye uyarlama, geçerlik ve güvenirlik ön çalışması [Adaptation of the test of early language development-third edition (TELD-3) into Turkish: Reliability and validity study]. International Journal of Early Childhood Special Education, 6(2), 151-176.

Henry, L. A., Messer, D. J., \& Nash, G. (2011). Executive functioning in children with specific language impairment. The Journal of Child Psychology and Psychiatry, 53(1), 37-45. https://doi.org/10.1111/j.1469-7610.2011.02430.x

Hutchinson, E., Bavin, E., Efron, D., \& Sciberras, E. (2012). A comparison of working memory profiles in schoolaged children with specific language impairment, attention deficit/hyperactivity disorder, comorbid SLI and ADHD and their typically developing peers. Child Neuropsychology, 18(2), 190-207. https://doi.org/10.1080/09297049.2011.601288

Just, M. A., \& Carpenter, P. A. (1992). A capacity theory of comprehension: Individual differences in working memory. Psychological Review, 99(1), 122-149. https://doi.org/10.1037/0033-295X.99.1.122

Kaçar, D. (2011). Anlamsız sözcük tekrar testi geliştirme çalışmast: Özgül dil bozukluğu olan çocuklarla ön çalışma bulguları [Developing a Turkish nonword repetiton test: Implementation with children with specific language impairment] (Tez Numarası: 288470) [Yüksek lisans tezi, Anadolu Üniversitesi]. Yükseköğretim Kurulu Ulusal Tez Merkezi.

Kapa, L. L., \& Erikson, J. (2019). Variability of executive function performance in preschoolers with developmental language disorder. Seminars in Speech and Language, 40(4), 243-255. https://doi.org/10.1055/s-0039-1692723

Kapantzoglu, M., Restrepo, M. A., Gray, S., \& Thompson, M. S. (2015). Language ability groups in bilingual children: A latent profile analysis. Journal of Speech, Language, and Hearing Research, 58(5), 15491562. https://doi.org/10.1044/2015 JSLHR-L-14-0290

Karasar, N. (2019). Bilimsel araştırma yöntemi, kavramlar ilkeler teknikler [Scientific research method, concepts principles techniques] (34. baskı). Nobel Akademik Yayıncılık.

Kim, Y. G. (2016). Direct and mediated effects of language and cognitive skills on comprehension of oral narrative texts (listening comprehension) for children. Journal of Experimental Child Psychology, 141, 101-120. https://doi.org/10.1016/j.jecp.2015.08.003

Korkmaz, B. (2005). Dil ve beyin: Çocuklarda dil ve konuşma bozuklukları [Language and brain: Language and speech disorders in children]. Yüce Yayınları. 
Kornilov, S. A., Lebedeva, T. V., Zhukova, M. A., Prikhoda, N. A., Korotaeva, I. V., Koposov, R. A., Hart, L., Reich, J., \& Grigorenko, E. L. (2016). Language development in rural and urban Russian-speaking children with and without developmental language disorder. Learning and Individual Differences, 46, 4553. https://doi.org/10.1016/j.lindif.2015.07.001

Kronenberger, W. G., \& Pisoni, D. B. (2016). Working memory training in deaf children with cochlear implants. In N. M. Young \& K. Iler Kirk (Eds.), Pediatric cochlear implantation: Learning and the brain (pp. 275292). Springer. https://doi.org/10.1007/978-1-4939-2788-3_18

Krzemien, M., Thibaut, J. P., \& Maillart, C. (2019). How language and inhibition influence analogical reasoning in children with or without developmental language disorder? Journal of Clinical and Experimental Neuropsychology, 42(1), 76-89. https://doi.org/10.1080/13803395.2019.1676881

Leonard, L. B. (2000). Children with specific language impairment. The MIT Press.

Leonard, L. B. (2001). Speech and language impairments in children causes, characteristics, intervention and outcome. In D. V. Bishop, \& L. B. Leonard (Eds.), Speech and language impairments in children (pp. 115-130). Psychology Press.

Lieberman, D. A. (2004). Learning and memory: An intagrative approach. Thomson Learning.

Mainela-Arnold, E., \& Evans, J. (2005). Beyond capacity limitations: Determinants of word recall performance on verbal working memory span tasks in children with SLI. Journal of Speech, Language, and Hearing Research, 48(4), 897-909. https://doi.org/10.1044/1092-4388(2005/062)

Mainela-Arnold, E., Evans, J. L., \& Coady, J. (2010a). Beyond capacity limitations II: Effects of lexical processes on word recall in verbal working memory tasks in children with and without specific language impairment. Journal of Speech, Language, and Hearing Research, 53(6), 1656-1672. https://doi.org/10.1044/1092-4388(2010/08-0240)

Mainela-Arnold, E., Evans, J. L., \& Coady, J. A. (2010b). Explaining lexical-semantic deficits in specific language impairment: The role of phonological similarity, phonological working memory, and lexical competition. Journal of Speech, Language, and Hearing Research, 53(6), 1742-1756. https://doi.org/10.1044/10924388(2010/08-0198)

Marton, K., Eichorn, N., Campanelli, L., \& Zakarias, L. (2016). Working memory and interference control in children with specific language impairment. Language and Linguistics Compass, 10(5), 211-224. https://doi.org/10.1111/lnc3.12189

Melby-Lervag, M., Lervag, A., Halaas-Lyster, S. A., Klem, M., Hagtvet, B., \& Hulme, C. (2012). Nonwordrepetition ability does not appear to be a causal influence on children's vocabulary development. Psychological Science, 23(10), 1092-1098. https://doi.org/10.1177/0956797612443833

Miller, A. L., Gross, M. P., \& Unsworth, N. (2019). Individual differences in working memory capacity and longterm memory: The influence of intensity of attention to items at encoding as measured by pupil dilation. Journal of Memory and Language, 104, 5-42. https://doi.org/10.1016/j.jml.2018.09.005

Milli Eğitim Bakanlığı [Ministry of National Education]. (2008). Özel eğitim ve rehabilitasyon merkezi dil ve konuşma güçlüğü destek eğitim programı [Special education and rehabilitation center language and speech difficulty support education program]. https://orgm.meb.gov.tr/meb_iys_dosyalar/2014_03/14093220_dilvekonumagldestekeitimprogram.pdf

Montgomery, J. W. (1995). Sentence comprehension in children with specific language impairment: The role of phonological working memory. Journal of Speech, Language, and Hearing Research, 38(1), 187-199. https://doi.org/10.1044/jshr.3801.187

Montgomery, J. W. (2000). Verbal working memory and sentence comprehension in children with specific language impairment. Journal of Speech, Language, and Hearing Research, 42(2), 293-308. https://doi.org/10.1044/jslhr.4302.293

Montgomery, J. W. (2002). Understanding the language difficulties of children with specific language impairments: Does verbal working memory matter? American Journal of Speech-Language Pathology, 11(1), 77-91. https://doi.org/10.1044/1058-0360(2002/009) 
Montgomery, J. W. (2003). Working memory and comprehension in children with specific language impairment: What we know so far. Journal of Communication Disorders, 36(3), 221-231. https://doi.org/10.1016/s0021-9924(03)00021-2

Montgomery, J. W., Magimairaj, B. M., \& Finney, M. C. (2010). Working memory and spesific language impairment: An update on the relation and perspectives on assessment and treatment. American Journal of Speech-Language Pathology, 19(1), 78-94. https://doi.org/10.1044/1058-0360(2009/09-0028).

Newbury, D. F., Fisher, S. E., \& Monaco, A. P. (2010). Recent advances in the genetics of language impairment. Genome Medicine, 2(1), 2-8. https://doi.org/10.1186/gm127

Norbury, C. F., Gooch, D., Wray, C., Baird, G., Charman, T., Simonoff, E., Vamvakas, G., \& Pickles, A. (2016). The impact of nonverbal ability on prevalence and clinical presentation of language disorder: Evidence from a population study. The Journal of Child Psychology and Psychiatry, 57(11), 1247-1257. https://doi.org/10.1111/jcpp.12573

Owens, R. E. (2004). Language disorders a functional approach to assessment and intervention (4th ed.). Pearson Education.

Özcebe, E., Erbas, A. N., \& Karahan-Tiğrak, T. (2019). Analysis of behavioural characteristics of children with developmental language disorders. International Journal of Speech-Language Pathology, 22(1), 30-36. https://doi.org/10.1080/17549507.2019.1571631

Peng, P., \& Douglas, F. (2016). A meta-analysis of working memory deficits in children with learning difficulties: Is there a difference between verbal domain and numerical domain? Journal of Learning Disabilities, 49(1), 3-20. https://doi.org/10.1177/0022219414521667

Pham, A. V., \& Hasson, R. M. (2014). Verbal and visuospatial working memory as predictors of children's reading ability. Archives of Clinical Neuropsychology, 29(5), 467-477. https://doi.org/10.1093/arclin/acu024

Prelock, P. A., \& Hutchins, T. L. (2018). Children with specific language impairment. In P. A. Prelock, \& T. L. Hutchins (Eds.), Clinical guide to assessment and treatment of communication disorders (pp. 53-64). Springer International Publishing.

Quam, C., Cardinal, H., Gallegos, C., \& Bodner, T. (2020). Sound discrimination and explicit mapping of sounds to meanings in preschoolers with and without developmental language disorder. International Journal of Speech-Language Pathology, 23(1), 1-12. https://doi.org/10.1080/17549507.2020.1750701

Riches, N. G., Laucas, G., Baird, G., Charmans, T., \& Simonoff, E. (2008). Sentence repetition in adolescents with specific language impairments and autism: An investigation of complex syntax. International Journal of Language \& Communication Disorders, 45(1), 47-60. https://doi.org/10.3109/13682820802647676

Rusli, Y. A., \& Montgomery, J. W. (2017). Children's comprehension of object relative sentences: It's extant language knowledge that matters, not domain-general working memory. Journal of Speech Language and Hearing Research, 60(10), 1-14. https://doi.org/10.1044/2017 JSLHR-L-16-0422

Santos, D. C., \& Ferre, S. (2018). A nonword repetition task to assess bilingual children's phonology children's phonology. Language Acquisition, 25(1), 58-71. https://doi.org/10.1080/10489223.2016.1243692

Schoff, K. (2019). Nonword repetition and word learning in children with specific language impairment [Undergraduate honors thesis, Butler https://digitalcommons.butler.edu/cgi/viewcontent.cgi?article=1490\&context=ugtheses

Schwering, S. C., \& MacDonald, M. C. (2020). Verbal working memory as emergent from language comprehension and production. Hypothesis and Theory, 14(68), 1-19. https://doi.org/10.3389/fnhum.2020.00068

Stokes, S. F., Klee, T., Kornisck, M., \& Furlong, L. (2017). Visuospatial and verbal short-term memory correlates of vocabulary ability in preschool children. Journal of Speech Language and Hearing, 60(10), 1-10. https://doi.org/10.1044/2017 jslhr-1-16-0285

Tabachnick, B. G., \& Fidell, L. S. (2018). Using multivariate statistics (7th ed.). Pearson Education. 
Tomblin, J. B., Records, N. L., Buckwalter, P., Zhang, X., Smith, E., \& O'Brien, M. (1997). Prevalence of specific language impairment in kindergarten. Journal of Speech, Language, and Hearing Research, 40(6), 12451260. https://doi.org/10.1044/jslhr.4006.1245

Turan, F. (2018). İletişim dil ve konuşma bozukluğu olan çocuklar. N. Metin (Ed.), Özel gereksinimli çocuklar [Children with special needs] içinde (2. bask1, ss. 179-226). Anı Yayınc1lı.

Vugs, B., Cuperus, J., Knoors, H., Hendirks, M., \& Verhoeven, L. (2017). Executive function training effects in children with SLI. In B. Vugs (Ed.), Executive functions in children with SLI: A dynamic perspective (pp. 141-160). Radboud University Nijmegen.

Vugs, B., Hendriks, M., Cuperus, J., \& Verhoeven, L. (2014). Working memory performance and executive function behaviors in young children with SLI. Research in Developmental Disabilities, 35(1), 62-74. https://doi.org/10.1016/j.ridd.2013.10.022

Vugs, B., Knoors, H., Cuperus, J., Hendriks, M., \& Verhoeven, L. (2016). Interactions between working memory and language in young children with specific language impairment (SLI). Child Neuropsychology, 22(8), 955-978. https://doi.org/10.1080/09297049.2015.1058348

Waters, G. S., \& Caplan, D. (2006). Language comprehension and verbal working memory. In L. Nadel (Ed.), Encyclopedia of Cognitive Science, (pp. 1-15). John Wiley \& Sons.

Ziethe, A., Eysholdt, U., \& Doellinger, M. (2013). Sentence repetition and digit span: Potential markers of bilingual children with suspected SLI? Logopedics Phoniatrics Vocology, 38(1), 1-10. https://doi.org/10.3109/14015439.2012.664652 


\section{Ankara University Faculty of \\ Educational Sciences Journal of \\ Special Education}

$2021,22(4), 871-893$
RESEARCH

Recieved Date: 28.05 .20

Accepted Date: 11.02 .21

OnlineFirst: 10.03 .21

\title{
Children with Developmental Language Disorders: Language Development and Verbal Working Memory*
}

\author{
Uğur Hassamancıŏglu (D)
}

Özcan Doğan $\mathbb{D}^{2}$

\begin{abstract}
Introduction: This study aimed to identify the relationship between language development and verbal working memory performances of children with developmental language disorders. The sample of the study consisted of 45 children between the months of 60-93 who received individual language and speech therapy. According to the educational evaluation of governmental institutions and organizations, it was decided that these children should only receive language and speech therapy.

Method: The data were obtained by using the Turkish Early Language Development Test (TELD) and the Working Memory Scale (WMS). The relationships between the sub-dimensions of verbal working memory and receptive, expressive, and verbal language development were examined.

Findings: According to the results, significant relationships were found between all sub-dimensions of verbal working memory and children's language skills. The relationship between verbal short-term memory and receptive language skills was found to be higher than expressive language skills. The language development and verbal working memory performances of children did not change depending on the duration of therapy.

Discussion: It was observed that children who have difficulties in language development regardless of their particular disability show different performances in the sub-dimensions of verbal working memory. It can be argued that a holistic and detailed assessment should be made by including cognitive processes along with language skills.
\end{abstract}

Keywords: Developmental language disorders, working memory, language development, specific language impairment, language skills.

To cite: Hassamancioğlu, U., \& Doğan, Ö. (2021). Children with developmental language disorders: Language development and verbal working memory. Ankara University Faculty of Educational Sciences Journal of Special Education, 22(4), 871-893. https://doi.org/10.21565/ozelegitimdergisi.742658

\footnotetext{
"This study was produced from the master's thesis of the first author entitled "Examination of Verbal Working Memory, Language and Attention Skills in Children with Specific Language Impairment.

${ }^{1}$ Corresponding Author: Lecturer, Cappadocia University, E-mail: ugur.hassamancioglu@kapadokya.edu.tr, https://orcid.org/0000-0003-4108-2885

${ }^{2}$ Prof., E-mail: Hacettepe University, ozcdogan@hacettepe.edu.tr, https://orcid.org/0000-0002-3006-8159
} 


\section{Introduction}

Developmental language disorder (DLD) is a disorder that occurs without any disability and falls under language disorders. In the Delphi Consensus CATALISE Panel, where experts working with children with language and speech disorders around the world came together, 'Developmental Language Disorders' was used to describe children who have language delays and/or problems (Bishop et al., 2017). This definition is used in this study, as well. Receptive and/or expressive language skills of children with DLD are low, considering cronological ages and intelligence quotients. It is known that children with DLD show typical development apart from their language development. The severity of DLD and the level of affecting children vary. The group of children with DLD is a heterogeneous group; children generally have problems in comprehension and production of language (Bishop, 2006). Language problems experienced by children with DLD arise when mental disability, hearing loss, motor disorders, any neurological disorder (Botting \& Conti-Ramsden, 2003) or autism spectrum disorder, difficulties resulting from brain damage, biomedical factors, such as epileptic aphasia are excluded (Özcebe et al., 2019). However, children with DLD have difficulties in reasoning and performing tasks that require executive functions (Kapa \& Erikson, 2019; Krzemien et al., 2019). In order to explain DLD, genetic (Leonard, 2000), neurobiological (Korkmaz, 2005) and cognitive factors continue to be investigated. On the other hand, the difficulties of children with DLD have among tasks such as speech perception, processing, storage, and language expression in cognitive processes suggest that they may have working memory (WM) problems (Owens, 2014). Varying rates (between 2.2\% and 7\%) have been reported for the prevalence of DLD in children depending on age and gender (Beitchman \& Brownlie, 2014; Norbury et al., 2016; Tomblin et al., 1997). Children with DLD show different characteristics in their language development and language-related skills (Turan, 2018) and generally have a poor vocabulary (Prelock \& Hutchins, 2018). Children with DLD experience difficulties in the morphological (Fortunato-Tavares et al., 2015; Leonard, 2001), semantic (Leonard, 2000; Owens, 2004), and pragmatic (Owens, 2004) components of language.

Working Memoy (WM) refers to a memory system where information is temporarily stored and processed at the same time. WM has limited capacity. The process of storing the incoming information temporarily by analysis of the WM components takes place gradually (Buchsbaum, 2016). In this study, the multi-componential WM Model of Baddeley was discussed. According to Baddeley, these components include visuo-spatial sketch pad (VSSP), phonological loop (PL) and central executive (CE) (Baddeley, 2003). In his later work, he also added the episodic buffer (EB) component to these components. Verbal Working Memory (VWM) "is responsible for the temporary storage of verbal information such as words, letters, numbers or all kinds of object names" (Dun \& Marien, 2016) and verbal information is actively kept here until used. (Buchsbaum, 2016). According to Baddeley, VWM is based on the PL component connected to the CE component (Pham \& Hasson, 2014). PL takes an active role in the process of learning linguistic output through perception in scientific processes, acquisition of new words, recalling and processing verbal inputs (Akoğlu \& Acarlar, 2014). The PL component consists of the passive 'phonological store' in which verbal information is held for about two seconds, and the active 'articulatory control process' structures in which the information is processed, which keeps the information current. These two components work collaboratively (Dun \& Marien, 2016). Some features of verbal knowledge affect the level of perception and processing of the information. These effects are related to WM performance (Baddeley \& Jarrold, 2007). These effects include "phonological similarity effect" (Baddeley, 2003) "the word-length effect" (Defilippi et al., 2019) and "irrelevant sound effect" (Buchsbaum, 2016).

VWM is closely related to language development. This relationship is exhibited in the literature examining the comprehension of language (Rusli \& Montgomery, 2017), production (Acheson \& Macdonald, 2009), word acquisition (Archibald, 2017; Stokes et al., 2017) and reading (Alloway et al., 2005; Lieberman, 2004). In order for the individual to understand the embedded expressions in the language and separate the verbal expression into its elements, it is necessary to reveal the individual's knowledge and blend it with new information (Waters \& Caplan, 2006). Due to the complex and limited capacity of WM, as information requiring storage and processing increases, WM performance decreases depending on individual differences. This theory has also been used to explain the problems experienced by children with DLD (Montgomery, 2003).

WM difficulties and language skills of children with DLD differ according to the typology of the languages, and the structures of different languages affect the WM performances of DLD children (Marton et al., 2016). It is recommended to consider the multi-componential WM model (Schwering \& MacDonald, 2020) and a holistic approach (Kronenberger \& Pisoni, 2016) to improve WM difficulties. 
Previous studies on WM difficulties and children with DLD report different results. For example, Marton et al. (2016) state that WM is associated with language difficulties. Kapantzoglu et al. (2015) report that the distinction between the presence or absence of language impairment in children may cause confusion with different diagnostic groups. There are studies that conclude that not all children with DLD experience WM difficulties (Archibald \& Joanisse, 2009) and that cognitive processes may be related to the language development of children with DLD (Archibald, 2017). Gray et al. (2019) state that not every child with WM difficulties has DLD and that typically developing children also have these difficulties.

There are studies in the literature including children with DLD about storage process in WM (Ebbels et al., 2012; Archibald \& Griebeling, 2016), processes in which CE is active (Henry et al., 2011) or processes where storage and processing are coordinated (Hutchinson et al., 2012). There are no studies in the literature that reveal the relationships between verbal short-term memory and WM, receptive-expressive and verbal language skills among Turkish-speaking children with DLD.

Considering the characteristics of children with DLD, the functioning and processes of the WM, and the component depending on the WM; the problems in WM, WM capacity and performance may refer to a reflection on language difficulties of children with DLD. In this direction, this study aimed to investigate the relationship between the difficulties experienced by children with DLD and VWM sub-dimensions, capacity and functioning. A limited number of studies were conducted in Turkey about Turkish-speaking children with DLD. This situation limits understanding the nature of the difficulties children experience, assimilating the relationship between language difficulties and DLD, and contributing to intervention programs developed for children. This research aims to fill this gap in the literature.

Also, the children included in the study receive individual speech and language therapy at different periods from private educational institution. Considering the effects of the duration of therapy on the VWM performance and language skills of the children, the relationship between the duration of the receive therapy with the VWM performance and language development was investigated. In this context, the following questions were sought in this study:

1. Is there a significant relationship between receptive-expressive and verbal language performances and VWM sub-dimensions and VWM performance in children with DLD?

2. Does the relationship between the receptive-expressive language and verbal language levels and VWM levels differ in children with DLD?

3. Do VWM performances and receptive-expressive verbal language skills differ depending on the duration of therapy among children with DLD?

\section{Method}

The correlation type of relational screening models was used in the research. "Relational screening are research models that aim to identify the presence and/or degree of covariance between two or more variables" (Karasar, 2019). Ethical permission was obtained from Hacettepe University (No: GO 19/129). The sample consisted of 45 children who were between 60 and 93 months, who received individual education in Special Education and Rehabilitation Center affiliated to Ministry of National Education in Ankara. Inclusion criteria of children in the research included the following: According to the evaluation results of the Counseling Research Centers (CRC), receiving only the "Developmental Language Module" (Educational assessment and diagnostic process of individuals with special needs is carried out by the CRC under the Turkish Republic Ministry of National Education. "The Developmental Language Module" includes the educational program used to support the receptive and expressive language skills of children with language and speech disorders as a result of educational evaluation and diagnosis [Republic of Turkey Ministry of National Education, 2008]), Turkish as the native language, lack of additional disability/diagnosis, receiving individual language and speech therapy sessions, and the chronological age including 60-95 months. Personal Information Form was used to obtain information about the demographic characteristics and the duration of therapy of children with DLD, The Working Memory Scale (WMS) (Ergül et al., 2018) was used to examine the VWM performance. The Turkish Early Language Development Test (TELD) (Güven \&Topbaş, 2015) was utilized to identify their language development. WMS results are expressed as 'very low, low, medium, high and very high' levels. There are 'non-word, digit and word recall' tasks in the short-term memory sub-dimension and 'first word and backward digit recall' tasks in the working memory sub-dimension in the WMS. In TELD, receptive-expressive and verbal language compound score are 
obtained at the end of the test. Test results are graded as "very poor, poor, below average, average, above average, good and very good".

Descriptive and correlation analyses were utilized. Using the skewness and kurtosis values, it was decided whether the data showed normal distribution. Relationships between variables were examined using parametric and non-parametric correlation analysis. One-Way Analysis of Variance was used to reveal the differences regarding the duration of the therapy on language development and VWM performance.

\section{Findings}

\section{Sub-dimensions of the VWM}

Children with DLD scored the highest from the 'non-word list recall' and the least from the 'first word recall' sub-dimensions of the VWM. The children with DLD received the lowest scores from the 'first word recall' task in the VWM sub-dimensions. \%93.3 of the children did not receive any score from 'first word recall' task. In the 'non-word recall' task, $53.1 \%$ of the children gave at least two correct answers to the items (the maximum number of correct answers given was 4).

\section{Relationship between Language Development and VWM}

According to the TELD result, all children with very poor levels were found to have very low VWM levels. None of the children with DLD was at 'high or very high' level according to WMS results.

\section{Table 1}

The Relationships Between VWM Standard Score and Sub-Dimensions and TELD Receptive, Expressive, and Verbal Language Compound Scores-Pearson and Spearman Correlation Coefficients

\begin{tabular}{lcccccc}
\hline & $\begin{array}{c}\text { VWM } \\
\text { standard } \\
\text { score }\end{array}$ & $\begin{array}{c}\text { VWM-digit } \\
\text { recall }\end{array}$ & $\begin{array}{c}\text { VW-word } \\
\text { recall }\end{array}$ & $\begin{array}{c}\text { VWM-non- } \\
\text { word recall }\end{array}$ & $\begin{array}{c}\text { VWM- } \\
\text { backward } \\
\text { digit recall }\end{array}$ & $\begin{array}{c}\text { VWM-first } \\
\text { word recall }\end{array}$ \\
\hline TELD-receptive score & $.528^{* *}$ & $.641^{* *}$ & .641 & $.389^{* *}$ & $.540^{* *}$ & .412 \\
TELD-expressive score & $.507^{* *}$ & $.480^{* *}$ & .452 & $.383^{* *}$ & $.477^{* *}$ & .161 \\
TELD verbal language compound score & $.552^{* *}$ & $.604^{* *}$ & .612 & $.405^{* *}$ & $.541^{* *}$ & .391 \\
\hline
\end{tabular}

Note: VWM = verbal working memory; TELD = the Turkish early language development test.

${ }^{*} p<.05{ }^{* *} p<.01$.

The correlation between VWM standard score and TELD verbal language compound score $(r=0.552 ; p$ $<.01)$ was found to be higher than TELD receptive $(r=0.528 ; p<.01)$ and expressive $(r=0.507 ; p<.01)$ language standard scores. TELD receptive language standard score showed a higher correlation with all sub-dimensions of VWM than expressive language standard score. The highest correlation between VWM sub-dimensions and TELD standard score was 'word recall' $(r s=0.641 ; p<.01)$, 'digit recall' $(r=0.641 ; p<.01)$ and TELD receptive language score. Among the TELD standard scores (receptive-expresive and verbal language compound), subdimensions of VWM, and VWM standard scores, there was no significant correlation only between TELD expressive language score and 'first word recall' $(r=0.161 ; p>.05)$. The changes in the duration of therapy received by children with DLD did not result in a significant difference in terms of the TELD and VWM standard scores.

\section{Discussion and Conclusion}

In this study, children had difficulties in the 'first word recall' most and 'non-word recall' least. The nonword recall sub-dimension is related to the phonological features of the words (Montgomery, 1995). As the number of non-word increases, it becomes difficult to keep the words in short-term memory. The children who participated in the study repeated the sequence of maximum four non-words. Non-word recall task determines the capacity of phonological short-term memory (Archibald \& Gathercole, 2007) and gives clues about the short-term storage processes of verbal information (Dun \& Marien, 2016). Marton et al. (2016) state that the nature of non-word recall is not fully understood yet, and this task can be a criterion for language processing like PL. Children with DLD can recall single-syllable words more easily (Dollaghan \& Cample, 1998), can recall a maximum of 10 nonwords (mostly monosyllabic) in a series of one to four syllables (Mainela-Arnold et al., 2010b) and have difficulty repeating non-words with three or more syllables (Archibald \& Gathercole, 2006a). It can be said that the word length effect (affecting the storage and processing process) influences the non-word recall task. The study results suggest that children keep non-words in PL for a short time and repeat them without the need for auditory 
perception and the coding process. At this point, the phonological similarity effect of non-word can be mentioned. The different acoustic and phonological features of the non-words may have been effective in keeping and repeating the information for a short time.

Children with DLD have difficulties mostly in 'first word recall' from VWM. This task that the CE component is active in WM; at the same time, the sentence must be completed, and the first word must be remembered. According to Baddeley (2010), in the Multi-Componential WM model, CE determines reminder strategies for information and performs rehearsal processes in order not to lose the information. PL also works as an auxiliary system under CE control. In the first word recall task, the individual must pass the audio input through phonological analysis, repetition process, recall, transformation and output in a short time (Baddeley, 2003). In the light of this information, it can be said that children with DLD have difficulties in keeping verbal information for a short period of time and performing cognitive and auditory processing at the same time.

In the study, the VWM sub-dimension that showed the highest positive relationship with receptive and expressive language skills was word and digit recall (See Table 1). The children participating in the study were able to recall a total of four digits in maximum. This result shows that language skills and verbal short-term memory are related. Similarly, previous studies show that receptive-expressive language skills are related to WM sub-dimensions such as word (Coady et al., 2012; Mainela-Arnold et al., 2010a) and digit (Frizelle \& Fletcher, 2015; Riches et al., 2008) recall that requires more storage (Gray, 2006; Vugs et al., 2016).

Language comprehension requires storing and processing verbal information. This process is demonstrated with different models: Limited WM capacity affects the storage and processing of information, therefore a choice is made between the storage and processing of information (Akoğlu, 2011). Some features of verbal knowledge (such as length, similarity, and close meaning) affect language acquisition in individuals with PL problems (Baddeley \& Jarrold, 2007) and new knowledge is associated with existing knowledge of the individual (Just \& Carpenter 1992). So, it can be said that possessing the grammatical knowledge previously by the sample group is effective on the receptive-expressive language and verbal language performances.

Previous studies state that children with DLD have difficulties in non-word recall, there is a high relationship between non-word recall task and their language skills, and DLD can be determined with this task (Dollaghan \& Campbell, 1998; Santos \& Ferre, 2018). On the contrary, there are studies concluding that there is a low (Gray, 2006; Mainela-Arnold et al., 2010b) or no (Melby-Lervag et al., 2012; Schoff, 2019) relationship between the non-word recall task and language skills. Coady and Evans (2010) mention three possibilities to explain the low relationship between non-word recall and language skills: (1) Inclusion critera of children with DLD in research (such as showing two standard deviation from the mean in language development or using standard tests), (2) data collection tools (the findings of each study are interpreted according to the characteristics of the relevant data collection tool), (3) non-word recall test suitability for DLD (measurement may not be reliable in children with attentional deficits or inadequate phonological awareness). In this direction, it is seen that studies investigating the relationship between non-word recall task and language skills have reached different results. For example, different data collection method (factors such as listening to non-words on a tape recorder, auditory similarity of words in a string of non-words, and resembling non-words to real (meaningful) words) may affect the results. As stated above, the sampling criteria, the characteristics of children with DLD and the measurement tools may explain the relatively low relationship between the language skills of children with DLD and non-word recall task.

While the backward digit task is related to the receptive-expressive language, the first word recall is only related to receptive language skills (See Table 1). One study shows that the tasks including first word recall, language comprehension and vocabulary are related (Ziethe et al., 2013). Archibald and Gathercole (2006b) state that children with DLD have problems with information storage. Vugs et al. (2014) also state that in the process of information storage and processing, it is difficult to overcome the cognitive load simultaneously.

It is seen that the processes involving the storage of information are more closely related to language skills than information processing. Considering the development of receptive-expressive language and the tasks and functions of PL, it is not surprising that the level of the receptive language relationship with VWM is higher than the expressive language. Previous studies show that children with DLD have difficulties in comprehending complex and long sentences (Montgomery, 2000), have poor articulation (Archibald \& Griebeling, 2016), and grammar and vocabulary (Kim, 2016) due to low WM capacity and performance. The children with DLD is a heterogeneous group. The difficulties that children experience in the components of the language also differ (Turan, 2018). Also, there may be other environmental (Kornilov et al., 2016), biological (Chen et al., 2017; 
Newbury et al., 2010) or different cognitive processes (Quam et al., 2020) that may be related to the language development of children with DLD. The difficulties experienced by children with DLD can be explained with more than one factor.

None of the children participating in the study showed high VWM performance. Children with DLD experience WM difficulties (Archibald \& Griebeling, 2016; Ebbels et al., 2012; Ergül et al., 2018; Hutchinson et al., 2012). A very low VWM level and average or below average scores of TELD were encountered. This is related to individual differences and the speech and language therapy services received by children. WM capacity varies from individual to individual. The individual's needs must be met in order for the WM to function fully (Daily et al., 2001). Therefore, factors such as the goals of the therapy, the methods used in therapy, information processing strategy, and attention skills will likely produce this result.

The children's language skills and VWM performances did not show a significant change according to the duration of therapy. Cognitive skills of children with DLD should be supported with alternative approaches such as memory use (Montgomery et al., 2010). Teaching PL strategies to children can be supportive to prevent language problems. These strategies include information processing (Montgomery, 2002). There are educational games that include tasks such as sequencing and memorizing auditory stimuli, word, digit, first word recall that strengthen VWM (Vugs et al., 2017). In the focus of WM, there are studies showing that strategy development (Dodwell \& Bavin, 2010), capacity utilization and methods aiming to manipulate more than one task support language development (Banales et al., 2015; Blacker \& Curby, 2014; Brewin \& Smart, 2005; Vugs et al., 2014). This study suggests that the content of the therapy, the methods and techniques used in teaching the skills, materials and programs prepared in a holistic way by focusing not only on language development but also on cognitive skills may be more supportive.

According to the results of this study, it was found that there was a correlation between the language development of children with DLD and VWM. The fact that children with very poor verbal language compound score also have a very low VWM performance supports this relationship. In the study, the development of the receptive language is more closely related to VWM. Children are more likely to keep verbal information in VWM, they have difficulties in processes that require active processing of verbal information. In addition, it was observed that pre-existing and familiar information in children had effects on children's receptive-expressive and verbal language performances.

Depending on the typology of the language and the VWM relationship, this study handles children with DLD whose native language is Turkish. In future studies, subjects such as attention skills, processing speed, new verbal knowledge acquisition and strategies for using this knowledge that may affect the language difficulties experienced by children with DLD can be investigated. The visual WM performances of the children could be evaluated, and their relationship with language development could be explored. The effects of VWM on skills including vocabulary, literacy, phonological awareness could be investigated. These effects could be considered in the preparation of intervention programs aimed at children with DLD.

Detailed evaluation of cognitive and language skills is needed within medical and educational settings. Although it is possible to consider and interpret the sub-dimensions of VWM separately while evaluating VWM in children, the Multi-Componential WM Model refers to a system in which the components of different tasks work together in coordination. Support programs could be prepared in a holistic manner by determining the strengths and weaknesses of the system. This is important for the realization of appropriate and evidence-based intervention.

\section{Author's Contributions}

The first author of the study took part in collecting the data. The analysis of the data used in the research, the writing process of the article and the arrangements were made with the support of both authors. 